\title{
DOCTRINA
}

\section{Teoría de la pena, concepto de delito y sistema del hecho punible en transformación ${ }^{1}$}

\author{
Theory of Punishment, Concept of Crime and System of Crime in Transformation
}

\author{
Wolfgang Frisch \\ Universidad de Friburgo
}

\begin{abstract}
RESUMEN El artículo se ocupa de tres círculos de problemas del Derecho penal que constituyen universalmente preguntas fundamentales de la disciplina. La primera parte del artículo se dedica a las teorías de la pena y aclara los cambios más importantes en ese ámbito. En la segunda parte, se abordan las transformaciones en el concepto de delito, que guardan estrecha relación con cambios en la teoría de la pena. En el centro de la tercera parte del artículo se sitúa el sistema del hecho punible. Este prácticamente no ha sufrido cambios relevantes en las últimas décadas. Las propuestas de reinterpretación de la categoría de la culpabilidad en clave de prevención ${ }^{2}$ no han tenido mayor resonancia, y el mismo destino ha tenido la crítica aislada frente a la distinción tradicional entre injusto y culpabilidad. ${ }^{3}$ La tesis de este trabajo es que el sistema del hecho punible exige una revisión urgente. Esto lo he intentado mostrar recientemente en una contribución crítica a la teoría de la imputación objetiva del resultado. ${ }^{4}$ Pero las dificultades e inconsistencias de la teoría de la imputación objetiva son únicamente una evidencia y un síntoma de la necesidad de revisión del sistema del hecho punible. El que este sistema ya no satisface las pretensiones de una dogmática diferenciada del hecho punible se vuelve más evidente si se consideran las transformaciones mencionadas en el ámbito de
\end{abstract}

1. El artículo se basa en la ponencia presentada el 22 de noviembre de 2018 en las XV Jornadas chilenas de Derecho penal y ciencias penales, celebradas en la Universidad Alberto Hurtado. Traducción de los profesores de Derecho penal Dr. Lautaro Contreras Chaimovich y Dr. Luis Emilio Rojas Aguirre (revisada por el autor).

2. Jakobs (1976: 7 ss.; 1991: 17/20 ss.; 2004: 17); en parte también Roxin (1974: 171 y ss.; 1979: 291 ss.; 2006: $\$ 19$ nm. 3 ss.).

3. Cfr., por ejemplo, Jakobs (1993a: 43 s.), Lesch (1999: 190 ss., 204 s.), Pawlik (2007a: 147 ss.; 2012: 276 ss.).

4. Véase Frisch (2018: 553 ss.). 
la teoría de la pena y de la concepción de la esencia del hecho punible. De esta manera se pone de manifiesto que nuestro sistema del hecho punible debe someterse a reflexión desde su fundamento y que necesita una serie de revisiones. ${ }^{5}$

PALABRAS CLAVE Fines de la pena, concepto de delito y sistema del hecho punible.

ABSTRACT The article deals with three circles of Criminal Law issues that universally constitute fundamental questions of the discipline. The first part of the article is concerned with the theories of punishment and clarifies the most significant changes in this area. The second part deals with the transformations of the concept of offense, which are closely related to the changes in the theory of punishment. At the core of the third part of the article is the system of crime. This system has suffered almost no relevant changes in the last decades. The proposals of reinterpretation of the category of culpability in terms of prevention have had no greater resonance, and the same fate has had the isolated criticism of the traditional distinction between wrongdoing and culpability. The thesis of this work is that the system of crime requires an urgent revision. I have recently tried to show this in a critical contribution to the theory of objective imputation of the result. But the difficulties and inconsistencies of the theory of objective imputation are only an evidence and symptom of the need for revision of the system of crime. The fact that this system no longer satisfies the pretensions of a differentiated dogmatic of the punishable act becomes more evident if one takes into account the transformations already mentioned in the field of the theory of punishment and the conception of the essence of the crime. This way it becomes manifest that our system of crime must be subjected to reflection from its foundation and that it needs a series of revisions.

KEYWORDS Aims of punishment, concept of offense and system of crime

\section{Transformaciones en el ámbito de la teoría de la pena}

Para comenzar este trabajo, abordaré las transformaciones en el ámbito de la teoría de la pena. ${ }^{6}$ La tesis planteada al principio, en el sentido de que aquí se han presentado cambios trascendentales en las últimas décadas, quizás puede sorprender a varios. En este escenario, la revisión de los manuales y otras exposiciones generales parece no confirmar la tesis. Así, uno todavía se topa con la presentación, sistematización y

\footnotetext{
5. Planteamientos al respecto ya en Frisch (2015a: 65 ss.; 2015b: 103 ss.); últimamente Frisch (2019e: $681 \mathrm{s.})$.

6. Acerca de las teorías sobre el fin de la pena (usualmente denominadas «teorías de la pena»), véase Nagler (1918). Más actual, por ejemplo, Radtke y otros (2004), Hassemer (2009), Hirsch y otros (2011); Hörnle (2011); Jakobs (1976: 7 y ss.); Pawlik (2004); Roxin (2015: 185 ss.); véase también Frisch (2012, 53 ss.), así como las contribuciones en Simester y otros (2014) (al respecto Ambos (2017: 297 y ss.) y últimamente Fischer (2018: 145 ss.)).
} 
valoración de la misma ronda variopinta de teorías que podía encontrar hace varias décadas atrás en obras similares. Solo por mencionar a las más importantes, entre ellas están las teorías absolutas y relativas, las teorías de la prevención y de la retribución, de la compensación y restablecimiento, y las teorías preventivas especiales y generales, estas últimas divididas en teorías negativas y positivas. ${ }^{7}$ Frente a esta situación, no pocas veces el lector tiene la impresión de que estas teorías siguen siendo tan actuales como antes.

En verdad, lo anterior es válido a lo sumo para una perspectiva puramente filosófica que cree poder someter a discusión una serie de postulados que ya no están disponibles para un jurista, como ciertos valores fundamentales de la Constitución, conexiones objetivas entre pena y hecho punible, pero también datos empíricos innegables. Si se observa la variopinta ronda de teorías de la pena desde este trasfondo, rápidamente queda claro que muchas de estas concepciones así presentadas son teorías «muertas». Lo son porque ellas se han vuelto incompatibles con postulados que ya no están disponibles para nosotros o con puntos de vista o conocimientos que ya no pueden cuestionarse seriamente. Muestra de lo anterior es que dichas teorías hoy en día apenas se sostienen enérgicamente en las discusiones serias sobre el fin determinante y la legitimación de la pena.

Teorías de la pena «muertas»: prevención especial, retribución y variantes empíricas de la prevención general

a) Al conjunto de teorías que se consideran «muertas» para la legitimación y la limitación de la pena pertenece la teoría de la prevención especial sostenida desde antaño por filósofos, según la cual el fin de la pena radica en la evitación de otros delitos del autor, sobre todo mediante su corrección o la seguridad frente a él. ${ }^{8}$ Lo cierto es que en la actualidad nadie plantearía de manera seria dejar sin pena al autor de un delito grave - por ejemplo, un homicidio- porque se ha arrepentido del hecho, y porque se espera que en el futuro no cometa más delitos o incluso es seguro que en el futuro no podrá cometer delitos igualmente graves. Sabemos que esta concepción no puede ser considerada porque, si fuera llevada a la práctica permanentemente, debilitaría la vigencia de normas importantes, y quizás incluso llegaría a ponerlas en cuestión. ${ }^{9}$ Sin

7. Véase, por ejemplo, Jescheck y Weigend (1996: 6o, especialmente 66 y s.); Jakobs (1991: 1/17 ss.); Roxin (2006: $\$ 3$ nm. 1 ss.).

8. Referencias de los representantes clásicos de esta teoría (Séneca y Platón) en Roxin (2006: $\$ 3 \mathrm{~nm}$. 11); sobre sus representantes en la época de la Ilustración, Nagler (1918: 294 ss., 305 ss., 339 ss., 357 ss.); como representantes modernos hay que nombrar especialmente a Franz v. Liszt (1883: 1 ss.), así como a la Défense sociale.

9. Cfr. Frisch (2015a: 77 s.; 2019e: 663 ss., 668 ss.); Jakobs (2004: 28 ss., 31 s.); Roxin (2006: 33 Rn. 19); Schünemann (1978: 236 ss.). 
embargo, cuando pensamos así, implícitamente partimos de una posición decidida acerca de las razones de necesidad de la pena y su fin. ${ }^{0}$

b) Por otra parte, una teoría de la pena que por mucho tiempo fue la dominante perdió resonancia en muchos Estados. Me refiero a la teoría de la retribución, que en su sentido originario busca retribuir o vengar al autor con el mismo mal o dolor que ha infligido a otro. ${ }^{11}$ Actualmente tampoco se encuentran formulaciones de este tipo en la jurisprudencia alemana, y con razón. Una intromisión en los derechos de sujetos titulares de derechos fundamentales solo con el fin de provocarles dolor, ciertamente excede el ámbito en que el Estado constitucional está autorizado a intervenir en los derechos de los ciudadanos, ${ }^{12}$ esto es, para el logro de las tareas esenciales del Estado. ${ }^{13}$ Esto es válido incluso si uno sostuviera que la retribución constituye una exigencia de la justicia, pues ciertamente el Estado debe proceder con justicia en el cumplimiento de sus tareas esenciales. Sin embargo, la persecución sin límites de postulados de la justicia no constituye por sí misma una tarea del Estado. ${ }^{14}$ Lo anterior rige con mayor razón cuando se trata, como ocurre con la retribución, de postulados de justicia intensamente discutidos y, en el mejor escenario, parcialmente compartidos.

c) Adicionalmente, una tercera teoría o grupo antiguo e importante de teorías se ha vuelto inaceptable en los Estados constitucionales modernos: la teoría de la prevención general en su variante empírica y psicosocial. ${ }^{15}$

En su formulación negativa, esta teoría toma el hecho realizado como un motivo para que mediante su castigo se influya con amenaza sobre otros delincuentes potenciales, ${ }^{16}$ lo que para la medida de la pena implica que esta debe orien-

10. Esto es, sobre su necesidad de mantener la vigencia fáctica de la norma; ver al respecto infra nota 27 y ss. Acerca de los numerosos argumentos en contra de la fundamentación preventivo-especial de la pena, confrontar con Frisch (2009: 391 ss.; 2015a: 71; 2012: 65 s.); Hörnle (2011, 20 ss.); Jakobs (1991, 1/40 ss., 47); Roxin (2006: $\$ 3 \mathrm{~nm} .16$ ss.).

11. Clásico al respecto Agustín de Hipona (2010: Sermón XIX, Art. 2); acerca de la influencia de este pensamiento en el derecho penal occidental, véase Frisch (2012: $56 \mathrm{~s}$.) con referencias ulteriores. Otra exposición completa del desarrollo y del contenido de la teoría de la retribución en Nagler (1918: 126 ss.). Apoyos a la teoría de la retribución en el último tiempo se pueden encontrar en Walter (2011, 636 ss.).

12. Argumentos adicionales al respecto en Frisch (2019a: II. 1), Roxin (1966: 378)

13. Acerca de este límite a la legitimación del Estado interventor, confrontar con las referencias en Frisch (2012: 58 ss., 70 ss.).

14. Con razón destacado por Roxin (1966: 378); acerca del desarrollo de esta comprensión en la época de la Ilustración, véase Frisch (2007: 252 ss.; 2012: 58 ss., 70 ss.); acerca de la perspectiva actual, Frisch (2015a: 70 s.), con ulteriores referencias.

15. Acerca de las distintas variantes de la teoría de la prevención general, confróntese Jakobs (1991: 1/4 ss. y 27 ss.); Jescheck y Weigend (1996: 68 s.); Roxin (2006: $\$ 3 \mathrm{~nm} .27 \mathrm{ss}$.).

16. Clásico en este sentido es Feuerbach con su «teoría de la coacción psicológica»; confrontar al respecto Feuerbach (1801: $\$ 16$ ss.). Ver en este sentido de manera complementaria Roxin (2006: $\$ 3 \mathrm{~nm} .22$ 
tarse a lo que parezca (empíricamente) necesario para intimidar a los potenciales delincuentes.

Esta teoría no solo es inaceptable porque a falta de conocimientos empíricos suficientes ${ }^{17}$ tiende a la ausencia de todo límite, sino porque instrumentaliza a los delincuentes o, con las palabras de Kant, ${ }^{18}$ los reduce a objetos del Derecho de bienes. Actualmente no estamos simplemente frente a una contravención a un postulado filosófico, como ocurría en la época de Kant. Tal instrumentalización del autor para los fines de otros contraviene hoy además el mandato constitucionalmente garantizado del respeto a la dignidad humana, que prohíbe el trato como objeto para las necesidades de otros. ${ }^{19}$

Lo dicho hasta ahora no solo rige para la teoría de la prevención general negativa en su variante empírico-psicosocial, sino también para la variante que con marcada tendencia muestra una cara más amable, como la teoría de la prevención general positiva, en tanto se conciba en términos puramente empíricos y psicosociales. También se instrumentaliza al autor cuando es castigado porque la conciencia jurídica de la población necesita ser reforzada y su castigo se orienta a lo que resulte (empíricamente) necesario para esos efectos. ${ }^{20}$ En este sentido, resulta sumamente problemático y, en todo caso, altamente equívoco, vislumbrar el fin y fundamento de la pena en el «ejercicio de la fidelidad al derecho». ${ }^{21}$ Lo anterior no es impedimento para que pueda existir una pena con un fundamento legítimo, fines y límites justificables, que al mismo tiempo pueda reforzar la conciencia jurídica y fomentar la fidelidad en el derecho, y que sea muy deseable con esos efectos positivos. ${ }^{22}$ Esto nos conduce a las teorías de la pena que todavía son aceptables y que, en definitiva, aún pueden sostenerse seriamente como teorías correctas.

ss.); Frisch (2014: 191 ss.); Greco (2009). Como representante moderno de una teoría de la intimidación preventivo general, véase Hoerster (1970: 272 ss.; 1972: 555 ss.).

17. Cfr. al respecto por ejemplo Schöch (1985: 1103 ss.; 1975: 262 ss.); Frisch (2010: 247 s.).

18. Confrontar con Kant (1797: Parte II, Sección 1 E).

19. Para la denominada prevención general negativa como teoría sobre el fin de la imposición de la pena, hoy reconocido (casi) generalmente; cfr. Badura (1964: 339 ss.), Köhler (1983: 40 y ss.); Warda (1962: 163 ss.); referencias ulteriores en Frisch (1998: 127 s., 137 s.).

20. Al respecto, véase Frisch (1998: 137 s.); Köhler (1983: 41 s.; 1997: 42); coincidiendo como representantes de una teoría de la prevención general positiva, véase Jakobs (2004: 32 ss.; 2012: 14 ss.); Pawlik (2007b: 482 ss.).

21. Véase Jakobs (1976, 9 s., 22 y 32; 1991: 1/15). En sentido similar, Joecks (2017: nm. 79).

22. Más en detalle acerca de estas relaciones, Frisch (2019e: 665 ss.). 
Las teorías todavía aceptables en la actualidad: confirmación de la vigencia de la norma para impedir un daño de vigencia, restablecimiento del estado jurídico

a) Estas teorías todavía aceptables tienen varios elementos en común. No castigan al autor simplemente (con motivo de su hecho) por necesidades empíricas de terceros (y según esta medida). Tampoco lo castigan para que sufra por haber cometido el hecho, sino que más bien lo castigan porque su hecho conlleva algo que no puede mantenerse así y que debe ser contrarrestado. Aquí, esta respuesta no se orienta solo de manera retrospectiva, sino que se entiende por sobre todo con la mirada puesta en el futuro, momento para el cual la pena ha de servir de algo. ${ }^{23}$

Esta concepción de la pena se encuentra, aunque no de manera tan clara, en formulaciones conocidas de la reciente jurisprudencia alemana. Según ella, la tarea de la pena radica en compensar la culpabilidad del autor, ${ }^{24}$ pero no solamente por la compensación de culpabilidad en sí misma, sino que en interés de la prevención. ${ }^{25}$ De esta manera, se explicita claramente que la pena cumple una tarea preventiva orientada al futuro y que de ella deriva su justificación. Sin embargo, el cumplimiento de esta tarea no obedece simplemente a las exigencias de necesidades empíricas de prevención (como en las diversas teorías de esta naturaleza). La prevención propia en la pena se limita a lo que puede lograr la pena medida según la entidad de la culpabilidad, o sea, la pena merecida conforme al injusto y la culpabilidad. Lo que no resulta tan claro en esta concepción, que une aspectos sustentados en el pasado y orientados al futuro, es la tarea de compensación de la culpabilidad también asignada a la pena. Pues cómo y en qué sentido la pena ha de poder compensar la culpabilidad, esto es, el injusto culpable, no es de recibo sin más. ${ }^{26}$

Desde esta perspectiva, mayor claridad y mejora traen consigo ciertas teorías de la pena, también planteadas en parte bajo la idea rectora de la prevención general positiva. ${ }^{27}$ Estas teorías instalan algo distinto en el lugar de la culpabilidad: un daño a la vigencia de la norma causado o amenazado mediante el hecho. Según ellas, la tarea de

23. Con razón en contra de la contraposición extendida entre las teorías obligadas por el punitur, quia peccatum est y aquellas que miran al futuro siguiendo la idea del punitur, ne peccetur, véase Jakobs (1991: $1 / 17)$.

24. Confrontar con BGHSt 24, 132, 134; 50, 40, 42. Véase también Haas (2008: 261 s.); Kühl (2007: 279).

25. Véase especialmente BGHSt 24, 40, 42 y muchas opiniones favorables en la literatura. Véase también el Primer Informe Escrito de la Comisión Especial para la Reforma del Derecho Penal, Deutscher Bundestag, Drucks. V/4094, p. 11.

26. Con razón crítico en este sentido, Roxin (1966: 378). Véase también Lesch (1999: 190 s.) y Schünemann (2014: 8), así como complementariamente Frisch (2015a: 70 s.).

27. Acerca de su (problemática) comprensión en el sentido de un «ejercicio en la fidelidad al derecho» (según las necesidades para ello existentes), véase las notas al pie 20 y 21. Acerca de las distintas variantes de la "prevención general positiva», véase Bloy (2013: 68 ss.). De manera completa, Kalous (2000: passim, especialmente 28 ss. y 130 ss.). 
la imposición de la pena consiste en igualar (o contrarrestar) un daño a la vigencia de la norma causado (o amenazado) por el hecho mediante una pena orientada a la medida de la culpabilidad. ${ }^{28}$ Es cierto que algunas veces se le ha reprochado a esta perspectiva que la idea del daño a la vigencia de la norma es poco clara y cuestionable, ${ }^{29}$ pero esta crítica a lo más se justifica en tanto los representantes de esta teoría posiblemente no han explicitado determinadas relaciones sencillas de esclarecer. Obviamente, no se plantea que el hecho aislado por sí mismo conduce a un daño perceptible y medible a la vigencia de la norma, y que luego resulte compensado mediante la pena correspondiente a esa medida. Más bien, se postula que se caería paulatinamente en una erosión de la vigencia de la norma (en el sentido del seguimiento fáctico) si no se reaccionara con pena al hecho punible , y tampoco (sometido al principio de igualdad de trato) frente a las respectivas lesiones de la norma que pudieran seguir sin reacción..$^{30}$ Me cuesta reconocer lo que aquí sería poco claro, oscuro o cuestionable; se ajusta a lo que nos enseña la razón práctica y la experiencia criminológica. Ciertamente, sería más claro referirse a que mediante la imposición de la pena tras el hecho cometido se procura impedir el peligro de otros daños a la vigencia de la norma, ${ }^{31}$ en vez de simplemente hablar de la compensación de un daño a la vigencia de ella. ${ }^{32}$ Sin embargo, esta breve aclaración no altera en nada el fundamento. Se trata de resguardar la vigencia de la norma lesionada y la eficacia preventiva de su sanción mediante la imposición de la pena después de cometido el hecho.

b) El hecho de que la amenaza e imposición de la pena una vez cometido el hecho, esto es, el instituto de la pena, sean imprescindibles, se evidencia particularmente en sectores donde cabe notar una extendida internalización insuficiente de la norma (disposición voluntaria al seguimiento de la norma), como en los delitos económicos y medioambientales, ${ }^{33}$ lo que también sucede en otros ámbitos. ${ }^{34}$ Contrarrestar la inminente erosión de la vigencia de la norma mediante el castigo del autor resulta asimismo justo, porque es este quien mediante su comportamiento genera, en ausencia de pena, el peligro de un daño a la vigencia de la norma que debe ser impedido ( $y$,

28. En este sentido, por ejemplo, Jakobs (2004: 24 ss., 32 ss.; 2012: 24 s.); Kalous (2000: 79 ss.); Neumann (1998: 151 s.); así como ya Frisch (1987: 386 ss., 780 s.; 2001a: 253 s.; 2002: 224 ss.; 2015a: 77); visión detallada sobre el contenido y representantes de esta teoría en Bloy (2013: 68 ss.); Streng (2012: nm. 24 ss.).

29. Confrontar con Hörnle (2013: 658 s.); crítico también Günther (1998: 165 s.); Haas (2008: 264); Koriath (1994: 243 s.).

30. En este sentido, correctamente, Jakobs (2004: 28); igualmente Frisch (2015a: 77; 2002: 224 ss.).

31. Del mismo modo ya Kalous (2000: 81) y Müller-Dietz (1983: 489).

32. Así, en parte Jakobs (2004: 31 ss.; 2012: 15) y también el propio autor de este artículo en contribuciones tempranas; ver, por ejemplo, Frisch (1987: 780 s.).

33. En detalle al respecto últimamente Feijoo (2017: 313 ss.).

34. Correctamente Feijoo (2017: 313 ss.); véase al respecto también Frisch (2019e: 669 ss.). 
según nuestra experiencia, que puede ser impedido mediante la pena). Por otro lado, también es correcto orientar la imposición de la pena no hacia las necesidades empíricas de prevención (por las cuales nada pueda hacer el autor), ${ }^{35}$ sino al significado que tiene el hecho punible en tanto lesión normativa para el ordenamiento jurídico en cuestión. ${ }^{36}$ Esto se expresa de mejor manera en el peso de la lesión normativa, es decir (en términos tradicionales), en la medida del injusto y de la culpabilidad del autor por este último. Ambos aspectos fijan la magnitud del cuestionamiento a la vigencia del ordenamiento jurídico mediante el hecho $y,{ }^{37}$ de este modo, también la medida de lo que el autor debe soportar para impedir a su costa el peligro de un daño a la vigencia de la norma. ${ }^{38}$

En lo esencial, suscriben la misma concepción los planteamientos formulados por varios autores en publicaciones recientes que asignan a la pena la tarea de reestablecer el derecho mediante la imposición de la afectación de derechos del autor, orientada a la medida del injusto culpable. ${ }^{39}$ Obviamente, esta concepción no se sostiene en el sentido de que la pena deba o pueda deshacer la lesión del derecho o reparar sus efectos reales, ya que esto último a lo más se puede lograr mediante prestaciones de reparación, etcétera. ${ }^{40}$ También aquí se trata de confirmar la vigencia e incolumidad del estado jurídico, incluidos los principios de igualdad y reconocimiento como regían antes $y$, asimismo, de reestablecer en este sentido (simbólico) el status jurídico fundamental que imperaba antes del hecho. ${ }^{41}$

\section{Resumen. Proyecciones de la teoría de la pena}

Como se ha dicho hasta ahora, la teoría de la pena ha experimentado importantes transformaciones en las últimas décadas. Esto significa que muchas de las teorías frecuentemente sostenidas desde antaño ahora son teorías «muertas» en lo fundamental. En este escenario, como teorías sostenibles del castigo se divisa solamente un puñado de ellas que son muy similares en su formulación, que se caracterizan por la síntesis

35. Correctamente Jakobs (2004: 32 ss.; 2012: 15).

36. En este sentido, en principio totalmente correcta (aunque también en parte tácitamente sobre la base de la teoría de la retribución) la jurisprudencia alemana. Confrontar con RGSt 58, 105, 109; BGHSt 3, 179; 20, 264, 266, Ver también Frisch (2000: 269 ss.).

37. En el sentido de una explicación, véase Frisch (2015a: 78 ss.; 2017: 376 ss.). En el sentido de una continuación en la medición de la pena y del necesario perfeccionamiento a su respecto, Frisch (2000: 278 ss.; 2015b: 106 s., 113 s.).

38. Véase Frisch (2015a: 77 s.). Coincidiendo en lo fundamental Jakobs (2004: 31 s.; 2012: 15).

39. Confrontar, por ejemplo, Pawlik (2004, 75 ss.); Frisch, (2000: 278 ss.; 2012: 72 s.) con ulteriores referencias; Murmann (2017: $\$ 8 \mathrm{~nm} .22 \mathrm{ss}$.); Zaczyk (2014: 90).

40. Frisch (2015a: 71); Roxin (2006: $\$ 3 \mathrm{~nm} .8$ ).

41. En este sentido también Frisch (2000: 278 ss.; 2012: 74 ss.); Haas (2008: 264 s.); Jakobs (2004: 32). 
de los momentos del restablecimiento (de la vigencia) y de la prevención (mediante el resguardo de la eficacia preventiva de la norma asegurada jurídicopenalmente), y que al mismo tiempo permite resolver el dilema de las contraposiciones tradicionales (como absolutas o relativas, orientadas al pasado o dirigidas al futuro). El trasfondo del acento puesto en un puñado de teorías muy cercanas en su fundamentación se explica, en gran parte, por una serie de reflexiones jurídico-constitucionales que han vuelto insostenible varias de las teorías frecuentemente defendidas.

El fin de la teoría de la pena debe consistir en ocuparse más intensamente de solo las teorías que todavía pueden sostenerse. En este sentido, se deben poner de relieve las diferencias, ventajas y debilidades de las diversas variantes para llegar a la mejor formulación posible de la teoría de la pena. Aquí es preciso deslindar, más claramente que antes, entre la función y legitimación efectivamente sostenible, legitimadora y limitadora de la pena, y entre las prestaciones que asimismo puede brindar una pena legítimamente impuesta y limitada según las convicciones de los miembros de una comunidad jurídica o que adicionalmente se le puede asignar ${ }^{42}$ como la satisfacción frente a la víctima o el restablecimiento de la relación de reconocimiento quebrantada.

\section{Transformaciones en el ámbito del concepto de delito}

Sobre la pregunta por la esencia del hecho punible, durante mucho tiempo imperó un consenso según el cual lo constitutivo era el daño o el peligro del objeto de un bien, lo que podía comprenderse como lesión de un bien jurídicamente protegido. Esta imagen objetivo-materialista del hecho punible no subyace solo en la concepción por mucho tiempo dominante del mismo, como un suceso disvalioso imputable al autor, cuya realización (o no evitación) se encuentra sometida a pena. ${ }^{43}$ También la visión del hecho punible, desarrollada e imperante durante el siglo XIX, como realización culpable y jurídico-penalmente valorada del injusto ${ }^{44}$, concibe a este último como algo plenamente observable, objetivo o material, cuya realización o no evitación se reprocha al autor con el juicio de culpabilidad. Esta imagen no fue alterada por el finalismo, incluso cuando varios planteamientos de Welzel sugieren una concepción diversa. ${ }^{45}$

42. Acerca de aquellas funciones de la pena dada las circunstancias en el caso concreto más o menos fuertemente cumplidas, y las relaciones decisivas en este sentido, Frisch (2019e: 665 s.).

43. Acerca del delito como «malum actionis» ya San Agustín (supra nota 11) y Hugo Grotius (1625); acerca de la exigencia de la imputación del suceso disvalioso especialmente Pufendorf (1672: libro 1, capítulo 5. $\$ \$ 1,3$, 5 ss.); más referencias (también acerca de la discusión posterior) en Frisch, (2018: 553).

44. Cfr. como resumen de este punto de vista y del fundamento del desarrollo posterior v. Liszt (1881: 64 ss., 70 ss.), Beling (1906), ulteriores referencias en v. Hippel (1930: 87 ss.).

45. Confrontar especialmente Jakobs (2015: 262 y 275): acción y hecho punible como «expresión de sentido». 


\section{Contraste de la teoría tradicional y objetivada con un concepto ideal (comunicativo, expresivo) de delito}

Recién en las últimas décadas se ha observado una cierta transformación en la concepción básica de la esencia del hecho punible. En las dos últimas décadas del siglo $\mathrm{XX}$, se multiplicaron las opiniones que veían a la esencia del hecho punible en algo ideal, expresivo, es decir, en un acto comunicativo. ${ }^{46}$ Según estas opiniones, para el derecho penal lo es esencial el cuestionamiento a la vigencia del derecho, su desconocimiento o menosprecio, que dota de contenido al suceso llamado hecho punible. El Estado reacciona con pena frente a ese cuestionamiento, no frente al injusto objetivo reprochable, para así reforzar la vigencia del derecho.

Ambas posturas mencionadas no conviven pacíficamente una junto a la otra desde hace tiempo. Los representantes de la concepción tradicional no solo se burlan de la postura que ve la esencia del hecho punible, y de la pena que reacciona ante él, en una interacción comunicativa. ${ }^{47}$ Este punto de vista reduccionista crearía una suerte de mundo artificial, ${ }^{48} \mathrm{y}$ debería rechazarse por una larga serie de razones. ${ }^{49}$ Los que sostienen un concepto comunicativo de la pena responden a estas críticas aduciendo que solo su concepción permite una armonía en la unidad del concepto de hecho punible y de pena, o mejor de la teoría de la pena, ${ }^{50}$ y que la distinción entre injusto y culpabilidad subyacente a la concepción tradicional del hecho punible carece de sentido. ${ }^{51}$ Quien intente mediar corre el riesgo de caer en el fuego cruzado de ambos frentes, pero quisiera intentarlo. Sin embargo, me parece que antes tiene sentido analizar brevemente de dónde proviene la discusión señalada.

46. Confrontar al respecto y sobre las caracterizaciones posteriores, por ejemplo, Jakobs (1983: 1/2 y 9 , 2/5) (bastante más destacado en la $2^{\text {a }}$ edición de 1991); véase también ya el mismo (1976: 25 s.); más claro el mismo (2004: 24 ss.); de los discípulos de Jakobs ver, por ejemplo, Feijoo (2007: 85 ss.); Lesch (1999: 210 ss.); Pawlik (2012: 55 s., 76 ss.); ver también Bloy (2013: 71 ss.); Freund (2009: \$1 Rn. 8 ss.; 2017: nm. 3); Haas (2008: 263 ss., 268 ss.); Köhler (1986: 9, 14 s., 69 ss.); Murmann (2013: 1135); Timm (2012: 43 ss., $55 \mathrm{ss}$.).

47. Cfr. Schünemann (2014: 7, 9 s.); Walther (2000: passim, especialmente 207 ss.).

48. Referencias a tales objeciones en la discusión sobre la conferencia «el principio de culpabilidad» ante la Rheinisch-Westfälischen Akademie en Jakobs (1993b: 27 nota al pie 31).

49. Un conjunto de objeciones en Stratenwerth (2007: 670 ss.).

5o. Confrontar en lo esencial Jakobs (1991, 1/2 s. y 9 s., 2/5; 2012: 13 s.); Pawlik, (2007b: 477 ss., 484 ss.); Freund (2017: nm. 3).

51. Confrontar con Jakobs (1993a: 43 s.; 2012: 24); Lesch (1999: 190 ss.); Pawlik (2007a: 147 ss.; 2012: 216 ss.). 


\section{Las transformaciones en la teoría de la pena como trasfondo de la evolución hacia un concepto (expresivo) ideal de hecho punible}

Mi tesis es simple: Las transformaciones en el concepto de delito tienen algo en común con los cambios relevantes anteriormente expuestos ocurridos en el ámbito de la teoría de la pena. Estas transformaciones suceden de modo paralelo al desarrollo de las teorías de la pena que asignan a la misma la función del reforzamiento de la vigencia de la norma o del impedimento de los daños a esta y que, fundadas en ella, la legitiman. Son fruto del esfuerzo por hacer compatibles la concepción básica del hecho punible con las teorías de la pena que hoy parecen fundar especialmente bien y convincentemente su legitimación. ${ }^{52}$ En particular: el concepto objetivado (o materialista) de hecho punible se encuentra íntimamente vinculado a la teoría de la retribución. Originariamente, este concepto describía el mal infligido por el autor, que era retribuido con otro mal (o cuya repetición debía conjurarse mediante la imposición de la pena). Con el paso del tiempo, la imputación del mal infligido por el autor se convirtió en presupuesto de la retribución justa. ${ }^{53}$ Posteriormente, esa función fue asumida por los conceptos de injusto y culpabilidad. ${ }^{54}$ De esta forma, este concepto objetivado (materialista) del hecho punible, determinado según el injusto y la culpabilidad, reinó mientras la retribución era considerada el fundamento de la teoría de la pena estatal y, asimismo, en tanto las concurrentes teorías empíricas de la prevención especial y general partían en la práctica de tal concepción objetiva del hecho punible.

Esta concepción objetiva del hecho punible se tornó dudosa y criticable cuando su base -el fundamento teórico sobre todo de la teoría de la retribución- se hizo sospechosa y fue crecientemente problemática. En Alemania, este proceso empezó unos años después de que entrara en vigencia la eficaz Constitución, que limitó el Estado al respeto de los derechos fundamentales y de la dignidad humana, al mismo tiempo que le autorizó a la intromisión en los derechos fundamentales solo bajo presupuestos muy estrictos y con fines reconducibles al ámbito de tareas propias del Estado, sujetos a un control racional. Desde este trasfondo, parecía osado sostener una teoría de la retribución donde el fin de la pena consistiera en provocarle un mal al autor para que este también sufriera..$^{55}$ En consecuencia, pocos años después de la entrada en vigencia de la Constitución, ya no se encuentran estas formulaciones en la juris-

52. Muy claro al respecto Jakobs (1991: 1/2 s. y 9 s.; 2012, 13 s.); Pawlik (2007b: 477 ss., 485 ss.).

53. Confrontar al respecto, en lugar de muchos, Hardwig (1957: 35 ss., 46 ss., 53 ss.); Hruschka (1976: passim; 1984: 679 ss.); Goeckenjan (2017: 63 ss.).

54. Véase al respecto Merkel (1867: 41 ss.); luego Binding (1890: 237 ss.); v. Liszt (1881: 83 ss., 95 ss.); resumen con ulteriores referencias en v. Hippel (1930: 182 ss.); correctamente sobre este cambio Mayer (1953: 102 s., 210 ss.).

55. Véase acerca de lo problemático de tal punto de vista, complementariamente, Frisch (2019a: especialmente II.1). 
prudencia. Pero también las versiones más moderadas de la teoría de la retribución en los términos de la compensación de culpabilidad mediante la pena ${ }^{56}$ cayeron bajo sospecha. Como fin en sí mismo, la compensación de la culpabilidad no es suficiente, incluso para la jurisprudencia más conservadora. También la compensación de la culpabilidad puede legitimar la pena solo en tanto sirve a la prevención, es decir, a una tarea racional del Estado. ${ }^{57}$ La doctrina, en particular la reformista de los años 60 y 70 del siglo XX, formula lo alegado en términos más drásticos. Según ella, la compensación de la culpabilidad por medio de una pena es pura metafísica, una profesión de fe que no puede constituir fundamento de la pena estatal en un Estado racional..$^{8} \mathrm{La}$ imposición de la pena después de cometido el hecho solo se justifica por la necesidad de reforzar la vigencia del ordenamiento jurídico y demostrar su incolumidad frente al hecho cometido. ${ }^{59}$ Estos planteamientos luego influyeron en la legislación de reforma. Entonces, la teoría de la retribución como fundamento de la imposición de la pena después de cometido el hecho fue sustituida por una teoría del necesario reforzamiento de la norma mediante pena, una teoría del reforzamiento de la vigencia de la norma que, lamentablemente, a menudo es caracterizada de manera muy inespecífica y equívoca, también a través del término de la "prevención general positiva», muy usual actualmente. ${ }^{60}$

El desarrollo expuesto en el ámbito de la teoría de la pena no podía quedar sin consecuencias para las formulaciones del concepto de delito. Teoría de la pena y concepto de delito forman una unidad, se encuentran recíprocamente conectados, ${ }^{61} \mathrm{y}$ son convincentes solo cuando son coherentes entre sí. Una concepción del hecho punible como un mal infligido a otro, que exige ser retribuido, era coherente con la teoría de la retribución. Que este mal infligido por el autor apareciera como injusto y que el autor tuviera culpabilidad en él, eran los presupuestos de la retribución justa del mal. Esta concepción del hecho punible ya no era sin más compatible con una teoría de la pena entendida como reforzamiento normativo y confirmación de la incolumidad de la vigencia de la norma: ¿por qué habría de reaccionarse a la provocación reprocha-

56. Confrontar en este sentido en la jurisprudencia, por ejemplo, BGHSt 24, 132, 134; 50, 40, 42; en la literatura, por ejemplo, Bruns (1974: 203, 311 s.) (compensación de la culpabilidad, principio de la culpabilidad-expiación); Kaufmann (1976: 271 ss.); véase también la fundamentación del Proyecto de 1962, pp. 96 s, 18 o s. y en el tiempo reciente Haas (2008: 261 ss.).

57. Ejemplar al respecto BGHSt 24, 40, 42.

58. Véase al respecto, en lugar de muchos, Roxin (1966: 378); ulteriores referencias en Haas (2008: 260), quien critica esta opinión (26o ss.) y menciona referencias de ulteriores voces críticas.

59. Claro en este sentido especialmente el Proyecto Alternativo de profesores de Derecho penal, Parte General, 2. ${ }^{a}$ ed. 1969, pp. 29 y 115.

6o. Acerca de la ambigüedad del concepto y las distintas corrientes, por ejemplo, Bloy (2013: 65 ss., 68 ss.); Kalous (2000: 28 ss., 130 ss.).

61. Así correctamente Jakobs (2012: 13 s.); Pawlik (2007b: 477 ss., 485 ss.). 
ble de un mal con el reforzamiento de la norma? Esto era comprensible solo cuando todavía se veía la esencia del hecho punible en algo distinto de un mal reprochable, algo que armonizara con la imposición de la pena como reforzamiento de la vigencia de la norma y la confirmación de su incolumidad, y que fuera razonablemente contrarrestado mediante una pena. La visión de la esencia del hecho punible que fundaba esta armonía era la concepción del hecho punible como puesta en cuestión a la vigencia de la norma lesionada por el hecho. Esta concepción del hecho punible ya se encontraba en el trasfondo de las justificaciones precedentes a la legitimación de la pena (más exactamente de su imposición), bajo la idea de la necesidad del reforzamiento de la norma tras el hecho cometido. ${ }^{62}$ Poco tiempo después, las formulaciones explícitas de un concepto ideal, expresivo o comunicativo de delito solo ponen de manifiesto esta concepción en el marco de exposiciones desarrolladas del concepto de delito. Algo similar ocurre con las referencias aparecidas en los años venideros al daño a la vigencia de la norma provocado o amenazado por la realización del hecho, ${ }^{63}$ y el uso de este concepto en el marco de la determinación de la pena. ${ }^{64}$

Con los elementos expuestos, ya tenemos suficiente información sobre el aspecto analítico, esto es, sobre la cuestión de las razones que condujeron, desde la década de los 80 del siglo XX, a encontrar cada vez más planteamientos a favor de una concepción ideal o expresiva del delito. Queda pendiente la pregunta sobre lo que puede sostenerse de este concepto expresivo de delito.

\section{Valoración: sobre la necesidad tanto del concepto objetivado como del ideal de delito}

Una valoración del concepto expresivo o ideal de delito sobre todo debiera prevenir las simplificaciones y distorsiones. Este concepto tiene su justificación, más aún, es imprescindible. Sin embargo, es un error plantearlo de manera absoluta, ya que también se justifica la existencia del concepto tradicional de hecho punible y, en buena medida, este también es imprescindible.

a) Es evidente que en la realización de un hecho punible existe también un menosprecio del derecho, un cuestionamiento a la vigencia de la norma lesionada en el caso concreto y, con ello, un cuestionamiento a la vigencia del derecho. ${ }^{65}$ No se nece-

62. O sea, el punto de vista especialmente del Proyecto Alternativo, p. 29 (fundamento del $\$ 2$ del Proyecto Alternativo): pena como «amarga necesidad por la existencia del ordenamiento jurídico».

63. Confrontar con Jakobs (1993a: 33 s.; 2004: 28 ss.; 2012: 13 ss.); Kindhäuser (1990: 33); Neumann (1998: 151).

64. Confrontar con Frisch (1987: 386 ss., 780 s.; 1993: 15, 18 y 23; 200o: 278 ss.; 2001a: 253) con ulteriores referencias; véase también Jakobs (2004: 30).

65. Véase al respecto ya Frisch (200o: 278 s.; 2001a: 253 s.; 2015a, 67, 77 s.); así como, por ejemplo -junto a Jakobs y sus discípulos (nota al pie 46)- Bloy, Freund, Haas, Köhler, Murmann, Timm (véase nota al pie 46). 
sita volver a Hegel ${ }^{66}$ para demostrarlo, ya el sentido común y la aproximación normal nos enseñan que esto es así. En este sentido, tratar o querer negar este aspecto del hecho punible sería algo difícil de comprender. ${ }^{67}$

Lo anterior es válido con mayor razón en tanto el concepto ideal o expresivo del hecho punible surge como imprescindible para poder fundar comprensiblemente la imposición de la pena en relación con el hecho cometido. ${ }^{68}$ Quien proponga prescindir de este aspecto del hecho punible y lo declare innecesario, tendría que, junto a su crítica del concepto ideal o expresivo de delito, estar en condiciones de ofrecer una justificación convincente y sujeta a exigencias racionales de la legitimación de la imposición de la pena tras el hecho cometido, prescindiendo de ese concepto del hecho punible. En este escenario, «sujeta a exigencias racionales» implica una justificación que evite constreñir a quien difícilmente puede aceptar la idea de compensación del injusto culpable mediante pena a una asunción de ella como manifestación de una suerte de profesión de fe. Así, la legitimación de la pena como reforzamiento (necesario) de la vigencia de la norma por el cuestionamiento de la misma mediante el hecho no lo constriñe a ello, y abre la posibilidad para quien puede aceptar las consecuencias de la pena como la compensación de la culpabilidad, de relacionar también estos efectos con la pena legitimada de otra forma.

b) Sin perjuicio de que el hecho punible tiene un imprescindible componente ideal para la legitimación de la pena, es errado reducirlo a este aspecto y rechazar totalmente la concepción tradicional. ${ }^{69}$ Lo que denominamos hecho punible de acuerdo con una convención en el lenguaje, siempre comprende un daño infligido a la víctima o a un bien, es decir, el contenido mayor o menor de injusto del hecho y la circunstancia de que este puede imputarse o reprocharse al autor del suceso. ${ }^{70}$ Esto no altera en nada que, en la perspectiva actual, la legitimación de la pena no pueda fundarse más en este aspecto del hecho punible, sino que para ello se requiere del aspecto ideal del hecho. Esto ni con mucho erige tal componente ideal en el hecho punible en su totalidad. Quien sostenga lo contrario no solamente corre el riesgo de

66. Especialmente $\$ 97$ en su «Grundlinien der Philosophie des Rechts», 1821.

67. Por otra parte, sería algo excesivo ver en el hecho punible, más allá del desprecio por el Derecho, un «diseño del mundo» por parte del autor o una «afirmación» de la no vigencia del Derecho. Véase al respecto Stratenwerth (2007: 670 y 674); Feijoo (2017: 313).

68. Véase más arriba en y después de la nota al pie 61; detalladamente Frisch (2015a: 77 s., 81 ss.; 2015b: 107 s.; 2019e: 658 ss.).

69. Esto en el sentido de una complementación de mis explicaciones acerca de la irrenunciabilidad del concepto de hecho punible ideal en Frisch (2015a: 77 ss.).

70. Esto es, al mismo tiempo, el núcleo legítimo de la crítica al denominado concepto de delito expresivo o ideal, por ejemplo, planteada por Schünemann (2014: 7 ss.); Hörnle (2013: 658); Walther (2000: 207 ss.); Zaczyk (2014: 85 s.). 
ser incomprendido por legos formados, sino también por avezados juristas..$^{71}$ Sobre este trasfondo, es comprensible la crítica mencionada sobre la concepción del hecho punible y la pena que reduce ambos conceptos al plano de la comunicación entre autor y Estado, y que al mismo tiempo soslaya la realidad del hecho punible con el dolor que este provoca a la víctima y a otros. Tal crítica cuestiona -no sin razón- una infradeterminación del concepto de hecho punible. ${ }^{72}$

La referida concepción tradicional además es imprescindible por razones procesales. El autor no es acusado o condenado simplemente por un cuestionamiento a la vigencia de la norma. Lo que se persigue, comprueba y enjuicia es un injusto objetivamente definido y exactamente determinado en sus detalles. Así, en la sentencia judicial condenatoria, se le reprocha al autor la realización de ese injusto. ${ }^{73}$ Incluso cuando en la actualidad la consecuente imposición de la pena ya no puede fundarse en la retribución de ese hecho comprobado y reprochado como tampoco convincentemente en la compensación de culpabilidad, sino que más bien solo se legitima frente al intolerable cuestionamiento del derecho al mismo tiempo implicado en el hecho punible, esto no altera que el hecho en sentido procesal y ciertos derechos procesales, ${ }^{74}$ tanto hoy como antes, se determinen mucho mejor mediante el concepto tradicional que el ideal de hecho punible. En mi opinión, esto también debería mantenerse así y no en último término por el interés en la aceptación de las correspondientes decisiones judiciales. ${ }^{75}$

Por todas estas razones, no se debería seguir discutiendo sobre el concepto tradicional o ideal de hecho punible en los términos de una disyuntiva de «todo o nada», ya que ambos componentes son necesarios para las tareas propias del derecho penal. Sería más trascendental discutir con mayor ahínco si surgen y en qué medida, consecuencias para el sistema del hecho punible a partir de la única legitimación plausible de la imposición de pena fundada en el concepto ideal de delito.

71. Yo mismo he tenido que manifestar esto en distintas discusiones sobre el concepto de hecho punible ideal. Confrontar con los propios planteamientos de Jakobs, reproducidos en Jakobs (1993b: 27, nota al pie 31).

72. En este sentido Zaczyk (2014: 83 ss.); véase también Frisch (2019e: 659 s.).

73. Acerca del contenido de la declaración de culpabilidad y de imposición de una pena especialmente incluido en tal reproche, Frisch (2019a: III); detalladamente acerca del contenido de la declaración de culpabilidad, Bloy (2013: 73 ss.); Maiwald (1971: 680).

74. Como el derecho de la persona afectada a participar como parte civil, a forzar, dado el caso, la acusación, el derecho de la víctima a conocer los registros de la investigación, etcétera.

75. Que no solo tienen como cometido el reforzamiento de la vigencia del derecho lesionado (como fin legítimo del castigo), sino que también persiguen otras finalidades, comenzando con la resolución del conflicto causado por el delito, pasando por el restablecimiento del derecho (al respecto nota al pie 35 ss.) hasta la satisfacción de los intereses de reparación de la eventual víctima; véase al respecto de manera complementaria Frisch (2019e: 659s., 665 ss.); Hörnle (2011: 35 ss., 37 ss.), Murmann (2004: 65 ss.). 


\section{Cambios necesarios en el ámbito del sistema del hecho punible}

Acerca de la necesidad de una adaptación del sistema del hecho punible a los cambios en la teoría del delito y en el concepto de delito fundamental

Hasta ahora se ha discutido relativamente poco acerca de las consecuencias que han tenido las transformaciones en el ámbito de la teoría de la pena y de la comprensión fundamental del delito en el sistema del hecho punible. ${ }^{76}$ Esto resulta verdaderamente sorprendente. Así como la teoría de la pena y el concepto de delito se sitúan en una relación recíproca, también el sistema del hecho punible está vinculado con la teoría de la pena y con el concepto básico de delito. El sistema del hecho punible constituye una diferenciación del concepto fundamental de delito y de la teoría de la pena. ${ }^{77} \mathrm{Si}$ la pena solo es legitimable por determinadas razones y para determinados fines, esto también tiene que ser considerado en los presupuestos del hecho punible. Adicionalmente, los presupuestos principales del hecho punible, que están ordenados en el sistema del hecho punible, deben concebirse de modo que, en caso de concurrir, la imposición de la pena pueda legitimarse. Asimismo, el sistema del hecho punible debe recoger, especificar y concretizar en sus categorías lo que forma parte de la comprensión fundamental del delito.

En este contexto, resulta evidente que el cambio en la teoría de la pena y en la comprensión básica del hecho punible también tiene como consecuencia ciertas transformaciones en el sistema del hecho punible. Tipo, injusto y culpabilidad fueron los presupuestos sistemáticos de un hecho punible concebido como mal. Si estos presupuestos concurrían, parecía justo, pero también necesario, reaccionar con el mal de la pena frente al mal realizado por el autor. Es improbable que estos presupuestos y sus elementos se vuelvan completamente irrelevantes a la luz de una comprensión fundamental del delito como cuestionamiento de la vigencia de la norma lesionada, y de una legitimación de la pena como confirmación de la vigencia de la norma necesaria para la mantención de su carácter vinculante. Al concepto ideal de delito también le interesa la conducta que contradice el derecho y, en este sentido, la conducta injusta. Y una calificación de esa conducta como cuestionamiento de la vigencia del derecho implica que la persona actuante sea capaz de decidirse correctamente, ${ }^{78} \mathrm{lo}$

76. Tampoco Jakobs, uno de los representantes principales del concepto de delito expresivo, ha tratado esta cuestión hasta ahora de manera completa, sino que se ha concentrado más en las consecuencias de su teoría de la pena, especialmente en el entendimiento de la culpabilidad. En relación con planteamientos propios, confrontar con Frisch (2015a: 83 ss.; 2017: 366 ss.; 2019e: 694 ss.).

77. Confrontar con Frisch (2019e: 648, 682 s.)

78. Confrontar con Frisch (2015a: 79 y 83; 2017: 371 s.); en esencia, del mismo modo, Jakobs (1993a: 41 ss., 43 s.; 2012: 59 s.). 
que presupone partes esenciales de la culpabilidad tradicional.79 Sin embargo, esa coincidencia no excluye, en principio, que la otra comprensión fundamental del delito y el cambio en la legitimación de la pena exijan, de manera más intensa, ocuparse de preguntas que uno pensaba que se podrían descuidar sobre la base de una comprensión tradicional del delito. Posiblemente, la nueva comprensión fundamental del hecho punible no se puede tener de manera gratis. Su aplicación puede hacer necesarios nuevos esfuerzos en el sistema del hecho punible y su diferenciación, que hasta ahora uno pensaba que se podría ahorrar.

En primer lugar, intentaré mostrar que los nuevos esfuerzos son necesarios y dónde lo son, pero también que valen la pena y que la nueva concepción del hecho punible solo ha hecho más evidente un déficit que existía hace tiempo. En segundo lugar, mostraré que la nueva comprensión del hecho punible y el nuevo fundamento de la teoría de la pena no solo exigen nuevos esfuerzos en el sistema, sino que también permiten eliminar problemas de encasillamiento y de sistematización existentes hasta ahora. Sería interesante ocuparse de la necesidad de revisión del sistema del hecho punible surgida a partir de los cambios que ha experimentado el fundamento de la teoría de la pena y la concepción básica del hecho punible, y también presentar una visión de conjunto del sistema del hecho punible que tiene que ser replanteado, sin embargo, esto implicaría superar los límites de extensión de este trabajo.

La desviación de la norma de conducta como categoría sistemática irrenunciable de un concepto de delito que presupone el cuestionamiento de la vigencia de la norma

Un aspecto decisivo en el que la adaptación del sistema del hecho punible a la concepción básica de este y al fundamento de la teoría de la pena hace necesario nuevos esfuerzos es fácil de advertir. Si se considera que la esencia del hecho punible está en el cuestionamiento de la vigencia de la norma que tiene que ser acatada y que la finalidad de la pena consiste en la confirmación de la vigencia de esa norma, se deben tener ideas claras sobre su contenido. Además, se deben poder formular y fundar de manera precisa esas ideas ${ }^{80}$ y estar en condiciones de esclarecer en qué medida y por qué el autor se ha desviado de la norma. Si se trata de un cuestionamiento de la norma por medio de la conducta del autor en el momento de la comisión del hecho, la norma tiene que estar formulada como norma de comportamiento de modo que,

79. O sea, la capacidad de decisión correcta (incluyendo la capacidad de reconocer el injusto del hecho).

8o. Con respecto a esto, sobre lo cual pueden presentarse, dado el caso, problemas considerables, confrontar con Frisch (1983: 74 ss., 118 ss.; 1988: 69 ss., 90 ss., 148 ss., 230 ss.; 2018: 561 ss.); Freund (1992: 51 ss.); Hoyer (2013: 223 ss., 232 ss.); Freund y Rostalski (2018: 264 ss.); Timm (2012: 40 ss., 64 ss., 242 ss.). 
en el momento del hecho, se pueda valorar si, por ejemplo, la conducta realizada contradice o no la norma.$^{{ }^{8}}$ Solo cuando esta última esté formulada de manera que esto se pueda valorar en el momento previo al hecho, la realización de una conducta por eso contraria a la norma, podrá calificarse también como un cuestionamiento de la norma por el sujeto actuante. ${ }^{82}$ En resumen, una aplicación convincente del concepto ideal de hecho punible y de la teoría de la pena que lo funda exige normas de comportamiento perfiladas de modo claro, referidas al momento de la actuación (de las cuales el autor se desvía y cuya vigencia pone, bajo ciertos presupuestos adicionales, en tela de juicio).

a) Es evidente que en la actualidad lo anterior no se ha logrado. Esto se muestra de manera clara en los delitos de resultado importantes en la práctica, como en los delitos de homicidio, los delitos de lesiones, los delitos contra la libertad o las formas delictivas concernientes a los daños. Quien espere hallar en esos delitos un plexo de normas de conducta con fuerza expresiva que guíen el comportamiento, que señalen lo en principio permitido y lo no permitido, y que delimiten lo uno de lo otro, sufrirá una decepción. La ley se limita a formular normas de sanción, que por sobre todo tienen en cuenta la mirada del aplicador del derecho y que están formuladas desde la perspectiva ex post (y en su terminología). ${ }^{8}$ En el momento previo a la comisión del hecho, la ley no le dice exactamente al ciudadano qué acciones están en principio prohibidas y cuáles están permitidas, teniendo en cuenta el conocimiento disponible. En este sentido, solamente en ciertos ámbitos centrales son posibles declaraciones en forma de inferencias seguras a partir de la norma de sanción. ${ }^{84}$ Un vistazo a la jurisprudencia y a la doctrina no conduce mucho más allá, ya que también se ocupan sobre todo de la diferenciación de las normas de sanción. De esta forma, la jurisprudencia y la doctrina se preguntan qué presupuestos deben reunirse para que la norma de sanción sea aplicable, si para lograrlo basta con una acción que represente una condición necesaria para el acaecimiento del resultado, o si se exige un vínculo más estrecho para que el resultado típico acaecido pueda imputarse, por ejemplo, la muerte. ${ }^{85}$ La pregunta relativa a qué normas de conducta tiene que cumplir el ciuda-

81. Véase por ejemplo Frisch (1983: 74 ss., 124 ss.; 1988: 4 O ss., 71 ss.; 2001b: 213, 234); Goeckenjan (2017: 230).

82. Y hacerse por este motivo al autor un reproche vinculado con la pena. Véase al respecto Bloy (2013: 73 ss.) así como Frisch (2019a: 548 ss.).

83. Fundamental Binding (1916: 3 ss., 19 ss., 35 ss., 42 ss., 63 ss., 132 ss., 153 ss.), quien precisamente distingue entre los tipos penales como normas de sanción y las normas lesionadas que estas presuponen, convirtiendo esto último en el objeto principal de su monumental obra de cuatro tomos; más detalladamente Frisch (2019b: secciones I y II).

84. Véase también al respecto Binding (1916: 46 ss.).

85. Así, especialmente, la cuestión planteada por la denominada teoría de la imputación objetiva, que entretanto ha encontrado acogida en la jurisprudencia. Véase al respecto Frisch (2018, 557 ss., 559 ss.). 
dano, considerando el conocimiento disponible, en el momento del hecho para no ser castigado por el tipo de sanción -en caso de acaecer el resultado típico- se encuentra apenas planteada, y en menor medida respondida de modo exhaustivo.

Quien quiera saber, por ejemplo, si infringe la norma de conducta que sirve de base al tipo de homicidio cuando hace entrega a otro de un determinado objeto porque a este último se le puede ocurrir la idea de matar a otro con dicho objeto, tendrá algunas dificultades para obtener una información clara acerca de las normas de conducta decisivas en este sentido. Algo similar ocurriría si él quisiera saber dónde están los límites entre los riesgos que conducen a la aplicación del tipo de sanción en caso de que estos se realicen, y los riesgos donde esto no ocurre. Como mucho, se pueden sacar conclusiones a partir de la imputación o no imputación del resultado en uno y otro caso, en el sentido de que en el primer supuesto probablemente se infringió una norma de conducta y en el segundo no. Sin embargo, estas conclusiones tienen una fiabilidad limitada y el ciudadano apenas puede deducirlas. ${ }^{86}$

Todo esto muestra que incluso en el ámbito de los bien estudiados delitos de resultado, actualmente no existe un sistema con bastante fuerza expresiva o simplemente un plexo de normas de conducta que le digan al ciudadano cuándo, en vistas a determinados tipos de sanción, se mueve en el marco de la conducta permitida en general, y cuándo no es el caso y su comportamiento tiene que considerarse como lesión de la norma de conducta requerida típicamente. Si se quisiera crear o hacer visible tal sistema o plexo de normas, serían necesarios ciertos esfuerzos dogmáticos. Lo mismo rige para una serie de otros delitos, pero debo prescindir de aclarar esto por razones de espacio.

b) Seguramente constituiría un error dar la espalda a la teoría de la pena y al concepto ideal de hecho punible aquí preconizados en virtud de la constatación precedente, no solo porque a ambos están vinculadas importantes ventajas, sino porque no hay ninguna alternativa realmente convincente frente a esta teoría de la pena y a la comprensión del hecho punible vinculado a ella. Más bien, la única consecuencia correcta puede consistir en eliminar el déficit que existe en la actualidad de normas de comportamiento que guíen la conducta y, de esta forma, crear los cimientos para la aplicación de la teoría de la pena y del concepto ideal de hecho punible. Desde mi punto de vista, esto es absolutamente posible y razonable, ya que el contingente de normas de conducta que tiene que ser establecido de esa manera está vinculado a una serie de ventajas para el Estado de derecho y para la eficacia del derecho penal, pero también para la práctica de los operadores.

86. Así, la no imputación del resultado puede tener su razón en que, por ejemplo, falta otro presupuesto (de la imputación) distinto a la infracción de una norma de conducta sobre la que se basa el tipo penal; y tampoco la simple no imputación en los casos en que falta tal lesión a una norma de conducta dejan suficientemente claro que el ciudadano se ha comportado correctamente. 
El hecho de que sea posible desarrollar este contingente de normas de conducta se puede ilustrar bien a través de los ya mencionados delitos de resultado. Es cierto que actualmente falta un sistema de normas adaptado a la perspectiva del ciudadano actuante y que le diga -considerando el conocimiento disponible antes de la acción- si y bajo qué presupuestos (dados o determinables ex ante) un comportamiento está en principio prohibido o en general permitido, todo esto con vistas al eventual acaecimiento del resultado típico. Sin embargo, este déficit es subsanable, y también debería ser subsanable de manera correcta sin la presión adicional del concepto ideal de delito. El déficit es subsanable puesto que importantes valoraciones necesarias para el desarrollo y la formulación de las normas de conducta que hay que establecer ya están disponibles actualmente en forma de ciertos presupuestos agrupados, sobre todo en la teoría de la imputación objetiva. ${ }^{87} \mathrm{Y}$ con independencia de la presión que ejerce el concepto ideal de delito, estas valoraciones reunidas actualmente en la teoría de la imputación objetiva del resultado deberían desarrollarse en el sentido de normas de conducta, ya que están situadas de manera equivocada en la teoría de la imputación objetiva ${ }^{88}$ Una serie de aparentes presupuestos de la imputación objetiva del resultado ya no conciernen a la cuestión de la imputación del resultado, sino a la cuestión de la conducta todavía permitida en general o injusta en principio, en el sentido de los delitos de resultado, como ocurre en el sentido de un delito de homicidio. Esto vale especialmente para la denominada primera parte de la fórmula básica de la imputación objetiva del resultado: ${ }^{89}$ la creación de un riesgo desaprobado de acaecimiento del resultado, y las constelaciones de casos señaladas por la teoría de la imputación objetiva en las cuales debería tratarse o no de tal creación de un riesgo desaprobado. Hace casi treinta años, fundamenté de manera intensiva que esa exigencia, en tanto peligro vinculado con la conducta, no es relevante recién para la imputación del resultado, sino que ya caracteriza aquello por lo cual la acción está prohibida. ${ }^{\circ} \mathrm{Un}$ sinnúmero de autores se ha mostrado de acuerdo con esta idea. ${ }^{91}$ Esta exigencia y

87. Confrontar con Frisch (2018, 561 ss.) y ya el mismo en (1988: 33 ss., 69 ss., 90 ss., 148 ss., 230 ss.), donde se expone en detalle qué afirmaciones de la teoría de la imputación objetiva dicen relación con el ámbito de la norma de conducta y que, en realidad, contienen afirmaciones acerca del carácter prohibido o no de una conducta y, con ello, marcan los límites entre uno y los otros.

88. Véase al respecto últimamente un resumen en Frisch (2018: 561 ss.) (con referencias a trabajos anteriores propios).

89. Confrontar con Frisch (2001b: 231 ss.) (con referencias a citas anteriores a la obra «Tatbestandsmäßiges Verhalten»); el mismo (2003: 733 ss.; 2018, 561 ss.).

90. Confrontar con Frisch, (1988: 33 s., 69 ss., 90 ss., 148 ss., 230 ss.) y las ulteriores referencias en la nota al pie anterior.

91. Confrontar con Eser y Burkhardt (1992: 3/99, 4/61, 64); Freund (2009: \$2 Rn. 12 ss., 72 ss.); Seher (2013: 207 ss.); Hoyer (2013: 223 ss.); Schmoller (2013: 237 ss.); Jakobs (2012: 30) (también ya el mismo, 1991: 7/4 ss.); Murmann (2017: \23 Rn. 29); Robles Planas (2016: 292 s.); SK-StGB/Rudolphi (1997: nm. 
los criterios positivos o negativos que la concretizan constituyen, por así decirlo, el cimiento y la base sobre los que se puede construir una dogmática empeñada en el desarrollo de normas de conducta decisivas.

Naturalmente, estas valoraciones no bastan por sí solas para establecer el instrumental de normas de conducta necesario para una aplicación convincente del concepto ideal de delito, es decir, comprobar que el autor ha infringido una o más normas de conducta presupuestas típicamente y la razón de esto. Para lograrlo, las valoraciones mencionadas necesitan de complementación en varios aspectos. Primeramente, habría que elaborar el contenido básico de la norma de conducta dirigida al autor que subyace en los delitos de resultado. Esa norma de conducta exige por parte de la persona actuante hacer uso de su libertad de modo que no conduzca a peligros inexigibles para los bienes jurídicos de terceros (su vida en el caso de delitos de homicidio o su integridad corporal y su salud en el caso delitos de lesiones, etc.). ${ }^{92}$ Esta norma de conducta básica debería ser concretizada un paso más allá, por ejemplo, bajo el aspecto de cuándo un peligro semejante no tolerable para terceros debería ser en principio aceptado, ${ }^{93}$ cuándo este es el caso tratándose de determinadas constelaciones, etcétera. ${ }^{44}$ En el marco de esta concreción, se pueden introducir muchas consideraciones ya elaboradas en el contexto de la teoría de la imputación y, de esta manera, se puede desarrollar un sistema de normas de conducta decisivas.

Asimismo, los delitos que a primera vista parecen describir por sí mismos la conducta prohibida, entre ellos muchos delitos de mera actividad como los delitos de expresión, el hurto y la caza furtiva, etc., todavía necesitan ser concretados de esta manera. Aquí también el tipo penal solo señala los presupuestos ex post de la sanción. Esto no es idéntico a la conducta que debe considerarse ex ante como prohibida. En realidad, contrario a la norma de conducta, ya es el comportamiento que, según las representaciones del autor o de manera objetiva, es idóneo de manera seria para

61); SK-StGB/Jäger (2017: nm. 96, 108); SK-StGB/Stein (2017: nm. 29); últimamente también Goeckenjan (2017: 230, 234, 270 s., 282, 285, 295 s.); antes ya Wolter (1981: 18 s., 31 ss.), al respecto más en detalle Greco (2018: 539 ss.), respectivamente con ulteriores referencias.

92. Véase al respecto Frisch (2018: 562 ss., 569 ss.) con ulteriores referencias. Detalladamente acerca del correcto entendimiento y el contenido de las exigencias de conducta a la luz de una comprensión del Derecho basada en la libertad, Zaczyk (2014: 73 ss., 88 ss.). Ver también Jakobs (2012: 26 ss.). Acerca de la cuestión de si esas exigencias de conducta se vinculan a un dato objetivo o a la evaluación subjetiva de los destinatarios de la norma, confrontar con Hoyer (2013: 223 ss., 232 ss.) (con referencias a mi concepción en los escritos más antiguos); Frisch (2019c: 623 ss.) y el mismo (2019f: 316) así como Timm (2012: 243 s.).

93. Véase al respecto Frisch (1988: 127 ss.).

94. Por ejemplo, en acaecimientos de resultado que amenazan solo a través de la conducta que tiene que enjuiciarse en vinculación con fuerzas de la naturaleza, con otras conductas de la víctima misma o a través de la conducta de terceros. Véase Frisch (1988: 90 ss., 148 ss., 230 ss.); asunción de esta sistemática en Freund (1992: 161 ss., 195 ss., 226 ss.); Goeckenjan (2017: 188 ss.). 
conducir a la realización del tipo de sanción. ${ }^{95}$ Otros indicios para una determinación precisa de las normas de conducta los proveen aseveraciones tradicionales acerca del tipo subjetivo y de la tentativa punible. De ellas se desprende, por ejemplo, que el sujeto actuante no cumple la norma de conducta en una declaración ante el tribunal cuando él, sin mencionarlo, presenta como verdaderas constelaciones fácticas ante el tribunal que él considera posiblemente falsas, incluso cuando la declaración en realidad sea verdadera. ${ }^{96}$ Por otra parte, el declarante no infringe la norma de conducta que subyace en el tipo de falso testimonio o de perjurio cuando lo que comunica al tribunal corresponde a su propia imagen del hecho, ya que comunicar esto es lo que le ordena, precisamente, la norma de conducta. ${ }^{97}$ Esto no cambia en nada si su imagen de lo sucedido tiene su origen en una percepción previa errada y en función de eso ha testificado algo objetivamente falso.

c) Las ventajas de resaltar las normas de conducta que subyacen a los tipos penales son enormes, ya que le dicen al ciudadano de manera mucho más clara que las normas de sanción qué formas de comportamiento constituyen injusto y llevan a la punibilidad. Con esto, las normas de conducta son deseables desde el punto de vista del Estado de derecho, ya que cumplen el mandato de determinación legal de la conducta punible mucho mejor que las normas de sanción, que dejan mucho en suspenso y que solo a través de presupuestos de sanción (judiciales) -difícilmente comprensibles para el ciudadano- se vuelven algo más claras. Esa mayor claridad y determinación no solo sirve a cada sujeto actuante, sino también beneficia a la protección de bienes jurídicos, impidiendo que tengan lugar afectaciones a estos, probablemente debido solo a la falta de claridad del orden de comportamiento. Asimismo, estas normas de comportamiento, formuladas de manera precisa (y confirmadas por la justicia), ofrecen una mucho mejor base para una internalización a largo plazo de la conducta jurídicamente correcta. Como puede mostrarse a través de una serie de ejemplos, incluso la praxis de los operadores de la justicia se beneficia de ellas.

En resumen, los nuevos esfuerzos necesarios para aplicar el concepto de hecho punible ideal y su trasfondo de teoría de la pena valen la pena por múltiples aspectos.

95. Al respecto más en detalle Frisch (1983: 346 ss., 357 ss.); acerca de la cuestión de si las correspondientes normas se vinculan a posibilidades objetivas y/o a representaciones de posibilidad subjetivas, confrontar con Frisch (1983: 349 ss., 357 s.), así como Frisch (2019c: 623 s.; 2019f: 316) así como Hoyer (2013: 223 ss., 232 ss.) y Timm (2012: 243 s.).

96. Pues entonces también infringe la norma de conducta (que puede ser fundamentada) consistente en no testificar ante el tribunal algo como verdad que él considera que no es verdad, por lo cual, aquí, aunque falta (por no haber falsedad) la realización del tipo de sanción, existe dadas las circunstancias una tentativa punible (inidónea), debido a la lesión de una norma de conducta vinculada a esa representación. Confrontar con Lenckner/Bosch (2014: nm. 15) y RGSt 50, 35, 36 (acerca de la cuestión paralela en el $\$ 263$ ).

97. Correctamente Rudolphi (1999: nm. 39 ss., 43) con ulteriores referencias. 
Solución de problemas de sistematización tradicionales y desestimaciones: La necesidad de refutación del cuestionamiento a través de la pena como categoría sistemática autónoma. ejemplos.

Independiente de estas y otras ventajas para un determinado derecho penal eficiente y apegado al Estado de derecho que están vinculadas con el desarrollo del orden de comportamiento jurídico, el concepto ideal de hecho punible y su trasfondo de teoría de la pena ofrecen a la sistemática misma del hecho punible también importantes beneficios. La comprensión del hecho punible como cuestionamiento de la vigencia de una norma y la legitimación de la pena como la reacción necesaria para la refutación de ese cuestionamiento, permiten también un encasillamiento material convincente de una serie de constelaciones de casos, con cuya sistematización la comprensión del hecho punible tradicional tiene problemas.

a) Quien legitime la imposición de la pena arguyendo que ella es necesaria para mantener la vigencia del derecho frente al hecho punible, entendido como un cuestionamiento de la vigencia del derecho, debe preguntarse qué es necesario para que se admita tal puesta en entredicho de la vigencia del derecho. En este sentido, los elementos que hay que encontrar son, primero, la desviación de la norma de conducta presupuesta en el tipo penal, segundo, que no pueda justificarse y, tercero, que pueda ser reprochada (imputada) al autor..$^{98}$ Sin embargo, los presupuestos mencionados no agotan el concepto de hecho punible, ya que también se requiere que sea necesario responder a ese cuestionamiento con la imposición de la pena. Solo cuando este sea el caso, la pena se puede legitimar y existe un hecho punible completo desde la perspectiva concerniente a la legitimación. ${ }^{99}$ Esto puede exigir, en ciertos casos, circunstancias adicionales, ya sean objetivas o subjetivas, junto a los presupuestos ya mencionados (desviación no justificada y reprochable al autor de la norma de conducta que presupone el tipo). ${ }^{100}$ No obstante, desde la perspectiva concerniente a la legitimación, también puede ser que un hecho punible no concurra, a pesar del cuestionamiento de la vigencia de la norma, porque no es necesario (o no aparece como necesario), por razones demostrables racionalmente, reaccionar al cuestionamiento de la vigencia de la norma que yace en el hecho. Desde un punto de vista sistemático, esto significa que el hecho punible, junto a categorías que diferencian el cuestiona-

98. En estos dos presupuestos adicionales (ninguna justificación de la desviación de la norma de conducta y la reprochabilidad de esa desviación) permanece inalterado en el sistema el hecho punible, el que ve su esencia en el cuestionamiento de la vigencia de la norma; los presupuestos de culpabilidad tradicionales consistentes en la capacidad de acatar la norma y la consciencia del injusto bien vistos son requisitos de que se pueda ver en la desviación de la norma un menosprecio por la misma. Confrontar con Frisch (2015a: 83; 2015b: 109; 2019e: 689 s., 695.).

99. Véase al respecto más en detalle Frisch (2015a: 84 s.; 2015b: 111 ss.).

100. Véase al respecto, con ejemplos adicionales, Frisch (2017: 372 ss., 377). 
miento de la vigencia del derecho, por razones concernientes a la legitimidad, contiene y debe contener una categoría que está guiada por la idea de la necesidad de la reacción con pena frente al cuestionamiento del Derecho. ${ }^{101}$

En esa categoría está la clave para el encasillamiento material correcto de una serie de constelaciones de casos, con cuya sistematización la teoría del hecho punible tradicional, orientada únicamente al injusto y la culpabilidad, ha tenido considerables problemas y se ha visto sobrepasada. Los problemas surgen porque a esta teoría le falta una categoría del hecho punible indispensable desde el punto de vista de la legitimación, lo que conduce a la imposibilidad de un encasillamiento material convincente de determinadas constelaciones de casos, o a que las únicas categorías disponibles se distorsionen y se reinterpreten para abarcar también esas constelaciones de casos. ${ }^{102}$ Los problemas cesan cuando se tiene presente que en un sistema fundado del hecho punible también se precisa una categoría de la necesidad de la aplicación de la pena, con la cual tienen que ver algunas constelaciones de casos e instituciones que no pueden insertarse en el injusto ni en la culpabilidad.

b) Un ejemplo importante de lo anterior lo constituye el desistimiento voluntario en la tentativa. Este no puede hacer desaparecer el injusto de la acción ya existente. Dado que el autor era capaz de evitar ese injusto, tampoco resulta posible negar el carácter culpable del mismo. Así, a la doctrina dominante no le queda otra salida que trasladar el desistimiento voluntario extramuros de las categorías materiales del injusto y de la culpabilidad, sin otra categorización que la mera causa personal de exclusión de la pena. ${ }^{103}$ Los autores que tratan de evitar esto último intentan encasillar el desistimiento en la culpabilidad como si de un tipo de causa de exclusión de la culpabilidad se tratara. ${ }^{104}$ No obstante, con esto el de por sí heterogéneo nivel sistemático de la culpabilidad se convierte en un sustrato todavía si cabe más abigarrado.

Todos estos problemas se resuelven tan pronto como se tiene en cuenta que, ya en forma de una especial categoría material del delito, solo pueden conducir a la condena y al castigo del autor aquel tipo de menosprecios del derecho cuya contradicción es todavía necesaria para el mantenimiento de la fuerza vinculante de la norma infringida. Desde la óptica del derecho alemán, precisamente esto es lo que falta en el supuesto en el que el autor abandona voluntariamente su hecho o ha impedido la producción del resultado que amenazaba. Quien se aparta así de su propio

101. Al respecto ya Frisch (2015a: 84 s.; 2015b: 111 ss.; 2017: 374 ss., 380 s.; 2019e: 688, 690 s., 695).

102. Esto rige especialmente para los intentos de tener en cuenta la problemática a través de su orientación a las necesidades de los fines de la pena, en Jakobs (1976: 7 ss., 14 ss.) y Roxin (1974: 181 ss.; 1979: 282 ss.). Al respecto con ulteriores referencias y crítica Frisch (2015a: 84 s.; 2017: 380 s.; 2019e: 686 ss., $691 \mathrm{s.})$.

103. Ejemplares al respecto por ejemplo RGSt 72, 349, 350; BGHSt 7, 296, 299; BGH StV 1982, 1; Jescheck y Weigend (1996: 548 y 553) con ulteriores referencias.

104. Así, por ejemplo, Roxin (1972: 36 ss.); Rudolphi (1993: nm. 6 s., con ulteriores referencias). 
cuestionamiento del derecho y regresa a la senda del mismo, revoca idealmente ese cuestionamiento y convierte en superfluo un rechazo expreso estatal a través de la condena reprobadora y la pena. ${ }^{105}$

c) La comprensión aquí desarrollada del hecho punible ofrece también una solución notablemente más satisfactoria que la ofrecida por el concepto tradicional de delito para la incardinación de las causas de exculpación. La ubicación de estas en la (falta de) culpabilidad -postulada por este concepto- da cuenta que el fundamento para la renuncia de la condena y la pena también se asienta en el ámbito de la culpabilidad. De esta forma, estas últimas quedan ancladas sistemáticamente en atención a la falta de culpabilidad, lo que implica considerar que el fundamento para la renuncia a la condena y a la pena se encuentra en el ámbito de la culpabilidad. Sin embargo, lo cierto es que en esos supuestos sucede algo distinto a lo que acontece en los casos en los que el autor no era en absoluto capaz de orientarse conforme a derecho, y en los que por lo tanto falta toda culpabilidad y cuestionamiento del derecho. ${ }^{106}$ Tanto el autor que se excede en su defensa como el que para conjurar peligros que se ciernen sobre su propia integridad física acaban sometiendo a otro a una situación de peligro para su propia vida, no actúan sin culpabilidad y desacatan igualmente de forma plena lo que el ordenamiento jurídico les requeriría en esas situaciones. ${ }^{107}$ Lo que realmente sucede en estos supuestos es que la medida del menosprecio del derecho ante tales situaciones excepcionales es claramente inferior a la que se da en el resto de supuestos, ${ }^{108} \mathrm{y}$ el cuestionamiento de la vigencia de la norma en este tipo de escenarios excepcionales, dada la disímil y comprensible situación motivacional, apenas debilita de forma relevante la vigencia del derecho. En general, lo que falta en estos supuestos es un cuestionamiento del derecho que haga a toda costa necesario reaccionar con una respuesta formal a modo de condena y castigo para el mantenimiento de la vigencia del ordenamiento jurídico en general. Lo mismo se puede afirmar en relación con una retahíla de causas de exclusión de la punibilidad presentes en la parte especial del Código Penal alemán.

\section{Visión panorámica}

Lo expuesto anteriormente debería limitarse por razones de espacio a destacar dos consecuencias especialmente importantes, que resultan de los cambios en la teoría

105. Frisch (2015a: 84 s.; 2017: 375); en la valoración material coincidente Roxin (1972: 37); similar Jakobs (1991: 26/1), quien habla de una «revocación de la expresividad de la ruptura de la norma».

106. Acerca de la diferencia a este respecto subsistente, Frisch (2019e: 689 s.).

107. Las normas de determinación jurídica, en el sentido de expectativa de omisión del actuar que se lleva a cabo, no están en ambos casos anuladas (con mayor razón tampoco las normas de valoración respectivas que califican la conducta realizada como jurídicamente equivocada).

108. En consecuencia, en el ámbito en el que es necesario asegurar la inquebrantabilidad del derecho. 
fundante de la pena y en un concepto de delito armónico con ella, conducentes a un sistema de categorías del hecho punible que da cuenta de ambas premisas. Posiblemente necesita todavía una que otra revisión adicional. También necesita una aclaración la función exacta, la relevancia y el contenido de la categoría tradicional del tipo en un sistema que no puede renunciar a la infracción -no justificada y culpable- de una norma de conducta. Todo esto no puede ser abordado aquí, pero demuestra una desiderata: aquello que aparece como urgentemente necesario es una investigación completa del sistema del hecho punible, surgido originalmente a partir de enfoques naturalistas y «salvado con dificultad» a través de muchas reparaciones de urgencia para mantenerlo a flote, ${ }^{109}$ de tal forma que esté en armonía con la teoría de la pena y con la comprensión fundamental del hecho punible compatible con esta última.

\section{Referencias}

Амвоs, Kai (2017). «Liberal Criminal Theory». Goltdammer's Archiv für Strafrecht, 164 (6): 297-323.

Agustín De Hipona. Sermones de Populum.

BADURA, Peter (1964). «Generalprävention und Würde des Menschen». Juristen Zeitung, 19 (11/12): 337-344.

Beling, Ernst (1906). Die Lehre vom Verbrechen. Tübingen: Mohr.

BInding, Karl (1872). Die Normen und ihre Übertretung. Tomo I. 1. ${ }^{a}$ ed. Leipzig: Engelmann.

-. (1890). Die Normen und ihre Übertretung. Tomo I. 2. ${ }^{\mathrm{a}}$ ed. Leipzig: Engelmann.

-. (1916). Die Normen und ihre Übertretung. Tomo I. 3. ${ }^{a}$ ed. Leipzig: Meiner.

Bloy, René (2013). «Symbolik im Strafrecht». En Georg Freund, Uwe Murmann, René Bloy y Walter Perron (editores), Grundlagen und Dogmatik des gesamten Strafrechtssystems, Festschrift für Wolfgang Frisch zum 7o. Geburtstag (pp. 59-80). Berlín: Duncker \& Humblot.

BRUns, Hans-Jürgen (1974). Strafzumessungsrecht, Gesamtdarstellung. 2. a ed. Köln: Heymann.

Cancio Meliá, Manuel (2014). «Überlegungen zu Wolfgang Frischs Beiträgen zur Unrechtsdogmatik». En Freund, Georg y Uwe Murmann (editores), Siebzig Jahre Wolfgang Frisch, Reden und Vorträge anlässlich der Übergabe der Festschrift zum 70. Geburtstag von Wolfgang Frisch (pp. 23-32). Tübingen: Mohr Siebeck.

EsER, Albin y Björn Burkhardt (1992). Strafrecht, Schwerpunkt Allgemeine Verbrechenselemente. Tomo 1. 4. ${ }^{\mathrm{a}}$ ed. Múnich: C.H. Beck.

FeIjoo, Bernardo (2007). «Positive Generalprävention. Gedanken zur Straftheorie Günther Jakobs'». En Michael Pawlik y Rainer Zaczyk (editores), Festschrift für

109. Así, la expresión utilizada correctamente por Cancio (2014: 24). 
Günther Jakobs: zum 7o. Geburtstag am 26. Juli 2007 (pp. 75-96). Berlín: Heymann. -. (2017). «La estabilización normativa como fin de la pena: ¿puro teatro?». En Jesús María Silva Sánchez, Joan J. Queralt Jiménez, Mirentxu Corcoy Bidasolo y María Teresa Castiñeira Palou (coordinadores), Estudios de derecho penal: homenaje al profesor Santiago Mir Puig (pp. 309-322). Montevideo: B de F.

Feuerbach, Paul Johann Anselm von (1801). Lehrbuch des gemeinen in Deutschland geltenden peinlichen Rechts. Gießen: Heyer.

FIsCher, Thomas (2018). Über das Strafen, Recht und Sicherheit in der demokratischen Gesellschaft. Múnich: Droemer.

FreUnd, Georg (1992). Erfolgsdelikt und Unterlassen, Zu den Legitimationsbedingungen von Schuldspruch und Strafe. Köln: Heymann.

-. (2017). «Vor $\$ 13 »$. En Wolfgang Joecks y Klaus Miebach (editores), Münchener Kommentar zum Strafgesetzbuch. Tomo 1. 3a ed. Múnich: C.H. Beck. Disponible en https://beck-online.beck.de/Home.

-. (2009). Strafrecht, Allgemeiner Teil, Personale Straftatlehre. 2. ${ }^{a}$ ed. Heidelberg: Springer.

Freund, Georg y Frauke Rostalski (2018). «Zu den Entstehungsbedingungen kontext - und adressatenspezifischer Ver- und Gebote sowie von konkreten Sanktionsanordnungen». Goltdammer's Archiv für Strafrecht, 165 (5): 264-273.

FrISCH, Wolfgang (1983). Vorsatz und Risiko, Grundfragen des tatbestandsmäßigen Verhaltens und des Vorsatzes, Zugleich ein Beitrag zur Behandlung außertatbestandlicher Möglichkeitsvorstellungen. Múnich: Heymann.

-. (1987). «Gegenwärtiger Stand und Zukunftsperspektiven der Strafzumessungsdogmatik». Zeitschrift für die gesamte Strafrechtswissenschaft, 99 (4): 349-388 y 751-806. DOI: 10.1515/zstw.1987.99.4.751.

-. (1988). Tatbestandsmäßiges Verhalten und Zurechnung des Erfolgs. Heidelberg: C.F. Müller.

—. (1993). «Straftatsystem und Strafzumessung. Zugleich ein Beitrag zur Struktur der Strafzumessungsentscheidung». En Jürgen Wolter (editor), 140 Jahre Goltdammer's Archiv (pp. 1-38). Heidelberg: Decker.

-. (1995). Tipo penal e imputación objetiva. Madrid: Colex.

-. (1998). «Schwächen und berechtigte Aspekte der Theorie der positiven Generalprävention. Zur Schwierigkeit der „Abschieds von Kant und Hegel«». En Bernd Schünemann, Andrew von Hirsch y Nils Jareborg (editores), Positive Generalprävention, Ergebnisse und Chancen der Forschung (pp. 125-146). Heidelberg: C.F. Müller.

-. (2000). «Strafkonzept, Strafzumessungstatsachen und Maßstäbe der Strafzumessung in der Rechtsprechung des Bundesgerichtshofs, Eine kritische-konstruktive Würdigung». En Claus Roxin y Gunter Widmaier (editores), 5o Jahre Bundesge- 
richtshof, Festgabe aus der Wissenschaft. Tomo IV (pp. 269-308). Múnich: C.H. Beck.

-. (2001a). «Unrecht und Schuld im Verbrechensbegriff und in der Strafzumessung». En Guido Britz (editor), Grundfragen staatlichen Strafens: Festschrift für Heinz Müller-Dietz zum 7o. Geburtstag (pp. 237-258). Múnich: C.H. Beck.

-. (2001b). «Faszinierendes, Berechtigtes und Problematisches der Lehre von der objektiven Zurechnung des Erfolgs». En Bernd Schünemann, Bernhard Haffke y Wilfried Bottke (editores), Festschrift für Claus Roxin zum 7o. Geburtstag am 15. Mai 2001 (pp. 213-238). Berlín: De Gruyter.

-. (2002). "Umstände der Strafzumessung außerhalb der Tat, Rechtsvergleichende und straftheoretische Überlegungen zur Strafzumessung». En Petter Asp, Carl Erik Herlitz y Lena Holmqvist (editores), Flores juris et legum, Festskrift till Nils Jareborg (pp. 207-236). Uppsala: Iustus.

-. (2003). «Zum gegenwärtigen Stand der Diskussion und zur Problematik der objektiven Zurechnungslehre». Goltdammer's Archiv für Strafrecht (150): 719-743.

-. (2007). «Rechtsphilosophie und Strafrecht in Europa». Goltdammer's Archiv für Strafrecht (154): 250-273

-. (2009). «Konzepte der Strafe und Entwicklungen des Strafrechts in Europa». Goltdammer's Archiv für Strafrecht, 156 (7): 385-405.

-. (2010). «Defizite empirischen Wissens und ihre Bewältigung im Strafrecht». En René Bloy, Martin Böse, Thomas Hillenkamp, Carsten Momsen, Peter Rackow (editores), Gerechte Strafe und legitimes Strafrecht, Festschrift für Manfred Maiwald zum 75. Geburtstag (pp. 239-262). Berlín: Duncker \& Humblot.

-. (2012). «Zur Idee der Strafe». En Peter Koslowski (editor), Endangst und Erlösung (pp. 53-82). Tomo II. Múnich: Fink.

-. (2014). «Feuerbachs Straftheorie und seine Strafbemessungslehre». En Arnd Koch, Martin Löhnig, Michael Kubiciel y Michael Pawlik (editores), Feuerbachs Bayerisches Strafgesetzbuch (pp. 191-208). Tubinga: Mohr Siebeck.

-. (2015a). «Strafe, Straftat und Straftatsystem im Wandel». Goltdammer's Archiv für Strafrecht, 162 (2): 65-85.

-. (2015b). «Straftheorie, Straftat und Strafzumessung im gesamten Strafrechtssystem, Zur Revisionsbedürftigkeit des Grundverständnisses der Straftat». En Christian Fahl (editor), Festschrift für Werner Beulke zum 7o. Geburtstag (pp. 103-114). Heidelberg: Müller.

-. (2017). «Strafwürdigkeit, Strafbedürftigkeit und Straftatsystem». Goltdammer's Archiv für Strafrecht, 164 (7): 364-382.

-. (2018). «Erfolgsgeschichte und Kritik der objektiven Zurechnungslehre - zugleich ein Beitrag zur Revisionsbedürftigkeit des Straftatsystems». Goltdammer's Archiv für Strafrecht, 156 (10): 553-572.

-. (2019a). «Zum Begründungshintergrund von Übel und Missbilligung (Tadel) in 
der Theorie der Strafe». Goltdammer's Archiv für Strafrecht, 166 (9): 537-553.

-. (2019b). «Bindings Bedeutung für die heutige Strafrechtswissenschaft». En: Michael Kubiciel et al (editores), Eine gewaltige Erscheinung des positiven Rechts. Tubinga: Mohr Siebeck, en prensa.

-. (2019c). «Untauglicher Versuch oder Wahndelikt? Überlegungen zu einem dogmatischen Problem aus der Perspektive der Normen - und der Straftheorie». En Goeckenjan, Ingke, Jens Puschke und Tobias Singelnstein (editores), Für die Sache, Kriminalwissenschaften aus unabhängiger Perspektive, Festschrift für Ulrich Eisenberg zum 8o. Geburtstag (pp. 617-639). Berlín: Duncker \& Humblot.

-. (2019d). «Straftheorie, Verbrechensbegriff und Straftatsystem im Umbruch». Goltdammer's Archiv für Strafrecht, 166 (3): 185-204.

-. (2019e). «Straftheorie, Verbrechensbegriff und Straftatsystem im Werk von Günther Jakobs». En Urs Kindhäuser, Claus Kreß, Michael Pawlik y Cark-Friedrich Stuckenberg (editores), Strafrecht und Gesellschaft, Ein kritischer Kommentar zum Werk von Günther Jakobs (pp. 647-696). Tubinga: Mohr Siebeck.

-. (2019f). «Untauglicher Versuch und Wahndelikt, insbesondere bei Irrtümern über ausserstrafrechtliche Normen». Goltdammer's Archiv für Strafrecht, 166 (5): 305-324.

GoecKenjan, Ingke (2017). Revision der Lehre von der objektiven Zurechnung: Eine Analyse zurechnungsausschließender Topoi beim vorsätzlichen Erfolgsdelikt. Heidelberg: Mohr Siebeck.

Greco, Luis (2009). Lebendiges und Totes in Feuerbachs Straftheorie, Ein Beitrag Zur Gegenwärtigen Strafrechtlichen Grundlagendiskussion. Berlín: Duncker \& Humblot.

-. (2018). «Objektive Zurechnung als Vorsatzgegenstand? Überlegungen aus Anlass des BGH-Urteils zum Göttinger Transplantationsskandal (BGHSt 62, 233)». Goltdammer's Archiv für Strafrecht 165 (9): 539-548.

Grotius, Hugo (1625). De jure belli ac pacis. Oxford: Clarendon Pr.

GÜNTHER, Klaus (1998). «Freiheit und Schuld in den Theorien der positiven Generalprävention. Ein Beitrag zur normativen Kritik». En Bernd Schünemann, Andrew von Hirsch y Nils Jareborg (editores), Positive Generalprävention, Ergebnisse und Chancen der Forschung (pp. 153-180). Heidelberg: C.F. Müller.

Hardwig, Werner (1957). Die Zurechnung, Ein Zentralproblem des Strafrechts. Hamburg: de Gruyter.

HaAs, Volker (2008). Strafbegriff, Staatsverständnis und Prozessstruktur, Zur Ausübung hoheitlicher Gewalt durch Staatsanwaltschaft und erkennendes Gericht im deutschen Strafverfahren. Tubinga: Mohr Siebeck.

Hassemer, Winfried (2009). Warum Strafe sein muss. Ein Plädoyer. Berlín: Ullstein. Hegel, Georg Wilhelm Friedrich (1821), Grundlinien der Philosophie des Rechts. Múnich: Saur. 
Hippel, Robert von (1930). Deutsches Strafrecht. Tomo II. Berlín: Springer.

Hirsch, Andreas von, Ulfrid Neumann y Kurt Seelmann (2011). Strafe - Warum?: Gegenwärtige Strafbegründungen im Lichte von Hegels Straftheorie. Baden-Baden: Nomos.

Hoerster, Norbert (1970). «Zur Generalprävention als dem Zweck staatlichen Strafens». Goltdammer's Archiv für Strafrecht 117: 272-281.

-. (1972). "Aktuelles in Schopenhauers Philosophie von der Strafe, Zur Generalprävention als dem Zweck staatlichen Strafens». Archiv für Rechts- und Sozialphilosophie, 58: 555-564.

Hörnle, Tatjana (2011). Straftheorien. Tubinga: Mohr Siebeck.

-. (2013). «Zur Relevanz von Beweggründen für die Bewertung von Tötungsdelikten - am Beispiel sog. „Ehrenmorde«». En Georg Freund, Uwe Murmann, René Bloy y Walter Perron (editores), Grundlagen und Dogmatik des gesamten Strafrechtssystems, Festschrift für Wolfgang Frisch zum 7o. Geburtstag (pp. 653-676). Berlín: Duncker \& Humblot.

Hoyer, Andreas (2013). «Umräumen von Möbeln auf offener Bühne». En Georg Freund, Uwe Murmann, René Bloy y Walter Perron (editores), Grundlagen und Dogmatik des gesamten Strafrechtssystems, Festschrift für Wolfgang Frisch zum 70. Geburtstag (pp. 223-236). Berlín: Duncker \& Humblot.

HruschKa, Joachim (1976). Strukturen der Zurechnung. Berlín: De Gruyter.

-. (1984). «Ordentliche und außerordentliche Zurechnung bei Pufendorf». Zeitschrift für die gesamte Strafrechtswissenschaft, 96: 661-702.

JäGER, Christian (2017). «Vor $\$ 1 »$. En Jürgen Wolter (editor), Systematischer Kommentar zum Strafgesetzbuch. Tomo I, 9a edición. Neuwied: Carl Heymanns.

JаковS, Günther (1976). Schuld und Prävention. Tubinga: Mohr.

-. (1983). Strafrecht, Allgemeiner Teil, Die Grundlagen und die Zurechnungslehre-Lehrbuch. Berlín: De Gruyter.

-. (1991). Strafrecht, Allgemeiner Teil, Die Grundlagen und die Zurechnungslehre-Lehrbuch. 2. ${ }^{a}$ ed. Berlín: De Gruyter.

-. (1993a). Der strafrechtliche Handlungsbegriff. Múnich: Beck.

-. (1993b). Das Schuldprinzip. Opladen: Westdeutscher Verlag.

-. (2004). Staatliche Strafe: Bedeutung und Zweck. Zúrich: Schöningh.

-. (2012). System der strafrechtlichen Zurechnung. Fráncfort del Meno: Klostermann.

-. (2015). «Welzels Bedeutung für die heutige Strafrechtswissenschaft». En Wolfgang Frisch et al (editores), Lebendiges und Totes in der Verbrechenslehre Hans Welzels (pp. 257-275). Tübingen: Mohr Siebeck.

JEsCHECK, Hans-Heinrich y Thomas Weigend (1996). Lehrbuch des Strafrechts, Allgemeiner Teil. 5. ${ }^{\mathrm{a}}$ ed. Berlín: Duncker \& Humblot.

JoEcKs, Wolfgang (2017). «Einleitung». En Wolfgang Joecks y Klaus Miebach (edi- 
tores), Münchener Kommentar zum Strafgesetzbuch, Tomo 1. 3a ed. Múnich: C.H. Beck. Disponible en https://beck-online.beck.de/Home.

Kalous, Angela (2000). Positive Generalprävention durch Vergeltung. Ratisbona: Roderer.

Kant, Immanuel (1797). Die Metaphysik der Sitten, Rechtslehre. 1. ${ }^{a}$ ed. Kaliningrado: Nicolovius.

Kaufmann, Arthur (1976). Das Schuldprinzip: eine strafrechtlich-rechtsphilosophische Untersuchung. 2. a ed. Heidelberg: Universitätsverlag Winter.

KindHÄUSER, Urs (1990). «Strafe, Strafrechtsgut und Rechtsgüterschutz». En Lüderssen, Klaus (editor), Modernes Strafrecht und ultima-ratio-Prinzip (pp. 29-46). Frankfurt am Main: Lang.

KöHLER, Michael (1983). Über den Zusammenhang von Strafrechtsbegründung und Strafzumessung. Heidelberg: Decker \& Müller.

—. (1986). Der Begriff der Strafe. Heidelberg: Decker \& Müller.

-. (1997). Strafrecht Allgemeiner Teil. Personale Straftatlehre. Heidelberg: Springer.

Koriath, Heinz (1994). Grundlagen strafrechtlicher Zurechnung. Berlín: Duncker \& Humblot.

KüHL, Kristian (2007). «Strafrecht in Anlehnung an Ethik/Moral». En Gerhard Dannecker (editor), Festschrift für Harro Otto zum 7o. Geburtstag am 1. April 2007 (pp. 63-78). Colonia, Múnich: Heymann.

LencKner, Theodor y Nikolaus Bosch (2014), «StGB \$154». En SchönkeSchröder, Strafgesetzbuch Kommentar. 29. ${ }^{a}$ ed. Múnich: C.H.Beck. Disponible en http:// beck-online.beck.de/Home.

Lesch, Heiko (1999). Der Verbrechensbegriff, Grundlinien einer funktionalen Revision. Colonia/Múnich: Heymann

LiszT, Franz von (1881). Deutsches Reichsstrafrecht. Berlín: Guttentag

-. (1883). «Der Zweckgedanke im Strafrecht». Zeitschrift für die gesamte Strafrechtswissenschaft, (3): 1-47.

Maiwald, Manfred (1971). «Das Absehen von Strafe nach $\$ 16$ StGB». Zeitschrift für die gesamte Strafrechtswissenschaft, 83 (3): 663-696. DOI: 10.1515/zstw.1971.83.3.663.

MAYER, Hellmuth (1953). Strafrecht Allgemeiner Teil. Stuttgart/Colonia: Kohlhammer.

Merkel, Adolf (1867). Kriminalistische Abhandlungen. Tomo I. Leipzig: Breitkopf und Härtel.

MülLER-Dietz, Heinz (1983). «Vom intellektuellen Verbrechensschaden». Goltdammer's Archiv für Strafrecht 130: 481-496.

Murmann, Uwe (2004). «Über den Zweck des Strafprozess». Goltdammer's Archiv für Strafrecht 151 (2): 65-86.

-. (2013). «Strafzumessung und Strafverfahren». En Georg Freund, Uwe Murmann, René Bloy y Walter Perron (editores), Grundlagen und Dogmatik des gesamten 
Strafrechtssystems: Festschrift für Wolfgang Frisch zum 7o. Geburtstag (pp. 11311152). Berlín: Duncker \& Humblot.

-. (2017). Grundkurs Strafrecht: Allgemeiner Teil, Tötungsdelikte, Körperverletzungsdelikte. $4 .^{\mathrm{a}}$ ed. Múnich: C.H. Beck.

NAGLER, Johannes (1918). Die Strafe: eine juristisch-empirische Untersuchung. Leipzig: Felix Meiner.

Neumann, Ulfrid (1998). «Normative Kritik der Theorie der positiven Generalprävention». En Bernd Schünemann, Andrew von Hirsch y Nils Jareborg (editores), Positive Generalprävention, Ergebnisse und Chancen der Forschung (pp. 147152). Heidelberg: C.F. Müller.

Pawlik, Michael (2004). Person, Subjekt, Bürger: Zur Legitimation Von Strafe. Berlín: Duncker \& Humblot.

-. (2007a). «Der wichtigste dogmatische Fortschritt der letzten Menschenalter? Anmerkungen zur Unterscheidung zwischen Unrecht und Schuld im Strafrecht». En Gerhard Dannecker (editor), Festschrift für Harro Otto zum 7o. Geburtstag am 1. April 2007 (pp. 133-154). Colonia/Múnich: Heymann.

-. (2007b). «Strafrechtswissenschaftstheorie». En Michael Pawlik y Rainer Zaczyk (editores), Festschrift für Günther Jakobs zum 7o. Geburtstag am 26. Juli 2007 (pp. 469-496). Colonia/Berlín: Heymann.

-. (2012). Das Unrecht des Bürgers. Tübingen: Mohr Siebeck.

Pufendorf, Samuel von (1672). De jure naturae et gentium. Londini Scanorum: Adam Junghans.

RadtKe, Henning, Egon Müller, Guido Britz, Heinz Koriath, Heinz Müller Dietz (2004). Muss Strafe sein?: Kolloquium zum 6o. Geburtstag von Herrn Professor Dr. Dr. h.c. Heike Jung. Baden-Baden: Nomos.

Roвles, Ricardo (2016). «Die «Lehre von der objektiven Zurechnung»: Gedanken über ihren Ursprung und ihre Zukunft». Goltdammer's Archiv für Strafrecht 163 (5): 284-293.

Roxin, Claus (1966). «Sinn und Grenzen staatlicher Strafe». Juristische Schulung: 377-387.

-. (1972). Kriminalpolitik und Strafrechtssystem. 2. ${ }^{a}$ ed. Berlín: De Gruyter.

-. (1974). "„Schuld« und „Verantwortlichkeit» als strafrechtliche System-kategorien». En Claus Roxin, Hans-Jürgen Bruns y Herbert Jäger (editores), Grundfragen der gesamten Strafrechtswissenschaft: Festschrift für Heinrich Henkel zum 70. Geburtstag am 12. September 1973 (pp. 171-198). Berlín: De Gruyter.

—. (1979). «Zur jüngsten Diskussion über Schuld, Prävention und Verantwortlichkeit im Strafrecht». En Arthur Kaufmann y Paul Bockelmann (editores), Festschrift für Paul Bockelmann zum 7o. Geburtstag am 7. Dezember 1978 (pp. 279-310). Múnich: C.H. Beck. 
-. (2006). Strafrecht Allgemeiner Teil Band I: Grundlagen. Der Aufbau der Verbrechenslehre. $4{ }^{\text {a }}$ ed. Múnich: C.H. Beck.

-. (2015). «Prävention, Tadel und Verantwortung - Zur neuesten Strafzweckdiskussion». Goltdammer's Archiv für Strafrecht 162 (4): 185-203.

RudolPHI, Hans-Joachim (1993). «\$ 20». En Jürgen Wolter (editor), Systematischer Kommentar zum Strafgesetzbuch. Tomo I, 8a edición. Neuwied: Carl Heymanns.

-.(1997). «Vor $\$ 1 »$. En Jürgen Wolter (editor), Systematischer Kommentar zum Strafgesetzbuch. Tomo I, 6a edición. Neuwied: Carl Heymanns.

-.(1999). «Vor $\$ 153 »$. En Jürgen Wolter (editor), Systematischer Kommentar zum Strafgesetzbuch. Tomo I, 6a edición. Neuwied: Carl Heymanns.

SChmoller, Kurt (2013). «Das „tatbestandsmäßige Verhalten» im Strafrecht». En Georg Freund, Uwe Murmann, René Bloy y Walter Perron (editores), Grundlagen und Dogmatik des gesamten Strafrechtssystems, Festschrift für Wolfgang Frisch zum 7o. Geburtstag (pp. 237-258). Berlín: Duncker \& Humblot.

Sснӧсн, Heinz (1975). «Grundlage und Wirkungen der Strafe - Zum Realitätsgehalt des $\$ 46$ Abs. 1 StGB -». En Gerald Grünwald y Friedrich Schaffstein (editores), Festschrift für Friedrich Schaffstein zum 70. Geburtstag am 28. Juli 1975 (pp. 255274). Göttingen: Schwartz.

-. (1985). «Empirische Grundlagen der Generalprävention». En Theo Vogler y Joachim Herrman (editores), Festschrift für Hans-Heinrich Jescheck zum 7o. [siebzigsten] Geburtstag (pp. 1081-1106). Tomo 2. Berlín: Duncker \& Humblot.

Schünemann, Bernd (1978). «Ungelöste Rechtsprobleme bei der Bestrafung nationalsozialistischer Gewalttaten». En Wolfgang Frisch y Werner Schmid (editores), Festschrift für Hans-Jürgen Bruns zum 7o. Geburtstag (pp. 223-248). Köln; Berlin; Bonn; München: Heymann.

-. (2014). «Ein neues Bild des Strafrechtssystems?». Zeitschrift für die gesamte Strafrechtswissenschaft, 126 (1): 1-26. DOI: 10.1515/zstw-2014-0001.

SEHER, Gerhard (2013). «Bestimmung und Zurechnung von Handlungen und Erfolgen». En Georg Freund, Uwe Murmann, René Bloy y Walter Perron (editores), Grundlagen und Dogmatik des gesamten Strafrechtssystems, Festschrift für Wolfgang Frisch zum 7o. Geburtstag (pp. 207-222). Berlín: Duncker \& Humblot.

Simester, A. P., Antje Du Bois-Pedain, Ulfrid Neumann (editores) (2014). Liberal criminal theory: essays for Andreas von Hirsch. Oxford: Hart Publishing.

STEIN, Ulrich (2017). «\$ 15». En Jürgen Wolter (editor), Systematischer Kommentar zum Strafgesetzbuch. Tomo I, 9a edición. Neuwied: Carl Heymanns.

Stratenwerth, Günter (2007). «Sachlogische Strukturen?». En Michael Pawlik y Rainer Zaczyk (editores), Festschrift für Günther Jakobs zum 7o. Geburtstag am 26. Juli 2007 (pp. 663-674). Colonia/Berlín: Heymann.

STRENG, Franz (2012). Strafrechtliche Sanktionen: die Strafzumessung und ihre Grundlagen, $3 .^{\text {a }}$ ed. Stuttgart: Kohlhammer. 
Tiмm, Frauke (2012). Gesinnung und Straftat, Besinnung auf ein rechtsstaatliches Strafrecht. Berlín: Duncker \& Humblot.

WALTER, Tonio (2011). «Vergeltung als Strafzweck». Zeitschrift für Internationale Strafrechtsdogmatik, 7: 636-647. Disponible en zis-online.com/dat/artikel/2011_7_599. pdf.

Walther, Susanne (2000). Vom Rechtsbruch zum Realkonflikt, Grundlagen und Grundzüge einer Wiedergutmachung und Strafe verbindenden Neuordnung des kriminalrechtlichen Sanktionensystems. Berlín: Duncker \& Humblot.

WARDA, Günter (1962). Dogmatische Grundlagen des richterlichen Ermessens im Strafrecht. Köln: Heymann.

WOLTER, Jürgen (1981). Objektive und personale Zurechnung von Verhalten, Gefahr und Verletzung in einem funktionalen Straftatsystem. Berlín: Duncker \& Humblot.

ZАCZYK, Rainer (2014). «Kritische Bemerkungen zum Begriff der Verhaltensnorm». Goltdammer's Archiv für Strafrecht, 161 (2): 73-90.

\section{Sobre el autor}

Wolfgang Frisch es catedrático emérito de Derecho penal de la Universidad de Friburgo de Brisgovia, Alemania. 
La Revista de Estudios de la Justicia es publicada, desde 2002, dos veces al año por el Centro de Estudios de la Justicia de la Facultad de Derecho de la Universidad de Chile. Su propósito es contribuir a enriquecer el debate jurídico en el plano teórico y empírico, poniendo a disposición de la comunidad científica el trabajo desarrollado tanto por los académicos de nuestra Facultad como de otras casas de estudio nacionales y extranjeras.

\author{
DIRECTOR \\ Álvaro Castro \\ (acastro@derecho.uchile.cl) \\ SITIO WEB \\ rej.uchile.cl \\ CORREO ELECTRÓNICO \\ cej@derecho.uchile.cl \\ LICENCIA DE ESTE ARTÍCULO \\ Creative Commons Atribución Compartir Igual 4.o Internacional
}

La edición de textos, el diseño editorial

y la conversión a formatos electrónicos de este artículo

estuvieron a cargo de Tipográfica

(www.tipografica.io). 